\title{
Oxyalkylated alcohols phthalates
}

\section{Authors:}

Albina R. Maskova,

Associate Professor, Applied and Natural Sciences Department, Ufa State Petroleum Technological University, Ufa, Bashkortostan Republic, Russia, asunasf@mail.ru;

\section{Guliya K. Aminova,}

Professor, Applied and Natural Sciences Department, Ufa State Petroleum Technological University, Ufa, Bashkortostan Republic, Russia, aminovagk@inbox.ru;

\section{Lyubov Z. Rolnik,}

Professor, General, Analytical and Applied Chemistry Department, Ufa State Petroleum Technological University, Ufa, Bashkortostan Republic, Russia, oax-ugntu@mail.ru;

\section{Galiya F. Faizullina,}

Engineer, Applied and Natural Sciences Department, Ufa State Petroleum Technological University, Ufa, Bashkortostan Republic, Russia, galiya.aminova@gmail.com;

\section{Aliya K. Mazitova,}

Professor, Head of Applied and Natural Sciences Department, Ufa State Petroleum Technological University, Ufa, Bashkortostan Republic, Russia, elenaasf@yandex.ru

\begin{abstract}
Polyvinyl chloride (PVC) is used to obtain a wide range of materials for various purposes. High demand of PVC is explained by possibility to modify polyvinyl chloride and produce broad range of materials with improved properties as well as to have cost efficient ratio: productivity, available raw materials, saving of natural resources. However, under normal temperature polyvinyl chloride is brittle and inelastic, that limits the fields of PVC application. The production of basic PVC compositions is impossible without plasticizers - low-molecular compounds that allow direct regulating physical and mechanical properties of polymer. Production of plasticizers became one of the most important branch of petrochemical industry. Recently, however, the range and production of plasticizers have drastically decreased due to the increased cost, which reduced the competitiveness of plasticized PVC products. Therefore, the expansion of plasticizer variety for PVC is a strategic task of great practical significance.

The present work describes synthesis methods of esters on the basis of oxyalkylated alcohols suggested as polyvinyl chloride plasticizers. Physico-chemical properties of synthesized compounds were studied. Conditions for their production with maximum outcome were selected. The results of experiments in which obtained compounds were tested as additives in the plasticization of PVC showed that the obtained samples of cable plastic, adhesive PVC tapes and multi-layered polyvinyl chloride linoleum satisfy all the technical requirements by the main indicators: cable plastic compound - GOST 5960-72 with amendment 1-9; a PVC adhesive tape - Technical Conditions - 2245-001-00203312-2003; multilayered linoleum - GOST 7251-77.

According to the experimental results, phthalates of oxyalkylated alcohols possess rather high efficiency as plasticizers of polyvinyl chloride and are recommended for use in the above-mentioned industrial PVC recipes.
\end{abstract}

Keywords: water sorption, soft cabel compound, PVC adhesive tape, multilayer linoleum, polyvinyl chloride plasticizers, tensile strain, breaking strength, melt flow index, thermostability, oxyalkylated alcohols phthalates.

Acknowledgements: The performed research has been funded through the government grant «Synthesis and investigation of the modern polyvinyl chloride plasticizers» according to the Decree of the Government of the Republic of Bashkortostan of 07.02.2018 №56 «On providing grants of the Republic of Bashkortostan to young scientists and groups of young researchers in 2018».

For citation: Maskova A.R., Aminova G.K., Rolnik L.Z., Faizullina G.F., Mazitova A.K. Oxyalkylated alcohols phthalates. Nanotehnologii v stroitel'stve $=$ Nanotechnologies in Construction. 2019, Vol. 11, no. 1, pp. 52-71. DOI: 10.15828/2075-8545-2019-11-1-52-71. 
Machine-readable information on CC-licenses (HTML-code) in metadata of the paper

<a rel="license" href="http://creativecommons.org/licenses/by/4.0/" ><img alt="Creative Commons License" style="border-width:0" src="https://i.creativecommons.org/l/by/4.0/88x31.png" / ></a $><$ br / ><span xmlns:dct="http://purl.org/dc/terms/" href="http://purl.org/dc/dcmitype/Text" property="dct:title" rel="dct:type" $>$ Oxyalkylated alcohols phthalates. $</$ span $>$ by $<$ a xmlns:cc="http://creativecommons.org/ns\#" href="Nanotehnologii v stroitel'stve = Nanotechnologies in Construction. 2019, Vol. 11, no. 1, pp. 52-71. DOI: 10.15828/2075-8545-2019-11-1-52-71" property="cc:attributionName" rel="cc:attributionURL">Maskova A.R., Aminova G.K., Rolnik L.Z., Faizullina G.F., Mazitova A.K. $</$ a $>$ is licensed under a $<$ a rel="license" href="http://creativecommons.org/licenses/by/4.0/" $>$ Creative Commons Attribution 4.0 International License</a $>$.<br/>Based on a work at $<$ a xmlns:dct="http://purl.org/dc/terms/" href="http://nanobuild.ru/en_EN/nanobuild-1-2019/" rel="dct:source" $>$ http://nanobuild.ru/en_EN/nanobuild-1-2019/</a $>.<b r />$ Permissions beyond the scope of this license may be available at $<$ a xmlns:cc="http://creativecommons.org/ns\#" href="asunasf@mail.ru" rel="cc:morePermissions" $>$ asunasf@mail.ru</a $>$.

The paper has been received by editors: 08.12.2018.

The paper has been received by editors after peer-review: 28.12.2018.

The paper has been accepted for publication: 25.01.2019.

\section{Фталаты оксиалкилированных спиртов}

\section{Авторы:}

Маскова Альбина Рафитовна,

доцент каф. «Прикладные и естественнонаучные дисциплины», ФГБОУ ВО «Уфимский государственный нефтяной технический университет», г. Уфа, Республика Башкортостан, Россия, asunasf@mail.ru;

\section{Аминова Гулия Карамовна,}

профессор каф. «Прикладные и естественнонаучные дисциплины», ФГБОУ ВО «Уфимский государственный нефтяной технический университет», Уфа, Республика Башкортостан, Россия, aminovagk@inbox.ru;

\section{Рольник Любовь Зелиховна,}

профессор каф. «Общая, аналитическая и прикладная химия», ФГБОУ ВО «Уфимский государственный нефтяной технический университет», г. Уфа, Республика Башкортостан, Россия, oax-ugntu@mail.ru;

\section{Файзуллина Галия Фатыховна,}

инженер каф. «Прикладные и естественнонаучные дисциплины», ФГБОУ ВО «Уфимский государственный нефтяной технический университет», г. Уфа, Республика Башкортостан, Россия, galiya.aminova@gmail.com;

\section{Мазитова Алия Карамовна,}

профессор, зав. каф. «Прикладные и естественнонаучные дисциплины», ФГБОУ ВО «Уфимский государственный нефтяной технический университет», г. Уфа, Республика Башкортостан, Россия, elenaasf@yandex.ru

Резюме: Поливинилхлорид (ПВХ) используется для получения широкого спектра материалов различного назначения. Высокий спрос на ПВХ связан с возможностью модификации поливинилхлорида и получением большого разнообразия материалов с улучшенными свойствами, а также с экономически обоснованным соотношением затрат - производительностью, доступным сырьем, экономией природных ресурсов. Однако при обычной температуре поливинилхлорид является хрупким и неэластичным, что ограничивает области применения ПВХ. Выпуск основных ПВХ-композиций невозможен без применения пластификаторов - низкомолекулярных соединений, которые позволяют направленно регулировать физико-механические свойства полимера. Производство пластификаторов стало одной из важных отраслей нефтехимической промышленности. Однако в последнее время ассортимент и производство резко сократились из-за возросшей себестоимости, что снизило конкурентоспособность пластифицированных ПВХ-изделий. Поэтому расширение ассортимента пластификаторов для ПВХ является приоритетным направлением и имеет практическую значимость.

В данной работе описаны методы получения сложных эфиров на основе оксиалкилированных спиртов, предложенных в качестве пластификаторов поливинилхлорида. Изучены физико-химические свойства синтезированных соединений. Подобраны условия их получения с максимальным выходом. Результаты испытаний полученных соединений в качестве добавок при пластификации ПВХ показали, что полученные образцы кабельного пластиката, ленты ПВХ липкой и многослойного поливинилхлоридного линолеума по основным показателям соответствуют всем техническим требованиям: кабельный пластикат - ГОСТ 5960-72 с изм. 1-9; лента ПВХ липкая - ТУ 2245-001-00203312-2003; многослойный линолеум - ГОСТ $7251-77$.

По результатам испытаний фталаты оксиалкилированных спиртов обладают достаточно высокой эффективностью как пластификаторы поливинилхлорида и рекомендуются для использования в вышеуказанных промышленных ПВХ-рецептурах.

Ключевые слова: водопоглощение, кабельный пластикат, лента ПВХ липкая, многослойный линолеум, пластификаторы поливинилхлорида, относительное удлинение, прочность при разрыве, температура текучести расплава, термостабильность, фталаты оксиалкилированных спиртов. 
Благодарности: Работа выполнена при поддержке научного гранта «Синтез и исследование современных пластификаторов поливинилхлорида», в соответствии с Постановлением Правительства РБ от 07.02.2018г. № 56 «О выделении в 2018 году грантов Республики Башкортостан молодым ученым и молодежным научным коллективам».

Для цитирования: Маскова А.Р., Аминова Г.К., Рольник Л.3., Файзуллина Г.Ф., Мазитова А.К. Фталаты оксиалкилированных спиртов // Нанотехнологии в строительстве. - 2019. - Том 11, № 1. - С. 52-71. - DOI: 10.15828/2075-8545-2019-11-1-52-71.

Machine-readable information on CC-licenses (HTML-code) in metadata of the paper

$<$ a rel="license" href="http://creativecommons.org/licenses/by/4.0/" ><img alt="Creative Commons License" style="border-width:0" src="https://i.creativecommons.org/l/by/4.0/88x31.png" / ></a $><$ br / > span xmlns:dct="http://purl.org/dc/terms/" href="http://purl.org/dc/dcmitype/Text" property="dct:title" rel="dct:type" > Oxyalkylated alcohols phthalates. $</$ span $>$ by $<$ a xmlns:cc="http://creativecommons.org/ns\#" href="Nanotehnologii v stroitel'stve = Nanotechnologies in Construction. 2019, Vol. 11, no. 1, pp. 52-71. DOI: 10.15828/2075-8545-2019-11-1-52-71" property="cc:attributionName" rel="cc:attributionURL">Maskova A.R., Aminova G.K., Rolnik L.Z., Faizullina G.F., Mazitova A.K. $</$ a $>$ is licensed under a $<$ a rel="license" href="http://creativecommons.org/licenses/by/4.0/" $>$ Creative Commons Attribution 4.0 International License $</ a>$. $<$ br / >Based on a work at $<$ a xmlns:dct="http://purl.org/dc/terms/" href="http://nanobuild.ru/en_EN/nanobuild-1-2019/" rel="dct:source" $>$ http://nanobuild.ru/en_EN/nanobuild-1-2019/</a $>.<\mathrm{br} />$ Permissions beyond the scope of this license may be available at $<$ a xmlns:cc="http://creativecommons.org/ns\#" href="asunasf@mail.ru" rel="cc:morePermissions">asunasf@mail.ru</a>.

Статья поступила в редакцию: 08.12.2018.

Статья поступила в редакцию после рецензирования: 28.12.2018.

Статья принята к публикации: 25.01.2019

\section{INTRODUCTION}

Polyvinyl chloride (PVC) is the most demanded volume polymer produced both in Russia and abroad. The reason for this is the exceptional ability to be processed by any means into a wide range of materials and products for various purposes. It is commonly known, in recent years there has been a tendency to an increase in the requirements for the operational and technological properties of materials and products obtained on the base of polyvinyl chloride. Therefore, additives must also meet the requirements.

More than 12 million tones of polymeric additives are produced every year in the world. The key role of chemical additives is to facilitate the processing of polymer blends and give necessary properties to finished products. Application of additives allows manufacturing a wide variety of products - from very soft, gel-like, to elastic, hard materials.

Plasticizers have the largest part among additives (more than 50\%). Esters of phthalic acid are at the first place in consumption.

The main representative of phthalate plasticizers is dioctyl phthalate (DOP), which is considered to be an international standard plasticizer for PVC that meets processing requirements. Its combination of properties is optimal, it is relatively cheap and provides the necessary complex of operational properties, but it belongs to substances of the second hazard class. However, DOP is still the most commonly used ester plasticizer for PVC [1...6].

Therefore, the development of new effective and ecofriendly plasticizers is relevant and has important practical importance.

\section{MAIN PART}

The authors are conducting research on the development of new plasticizers [7...17]. This paper describes methods of synthesis, some physic-chemical properties and results of tests of oxyalkylated alcohol phthalates in several PVC-composition for construction purposes, specifically: in the recipes of cabel PVC-plasticate O-40 rec. OM-40 (black), PVC adhesive tape and multilayer linoleum.

Target esters with third class of hazard are obtained in two stages. At the first stage oxyalkylated alcohols are synthesized. Then by esterification of oxyalkylated alcohols with phthalic anhydride final products are obtained.

\section{Method of oxyalkylating of alcohols}

A four-necked flask equipped with a stirrer, a thermometer, a reflux condenser, and a device for introducing ethylene oxide (propylene) is charged with the calculated amount of alcohol and catalyst - sodium hydroxide. The reactor is heated in an oil bath and blow of with nitrogen to remove air. Then gradually (with the running mixer), ethylene (propylene) oxide is introduced. The rate of ethylene (propylene) oxide feeding is adjusted so that the unreacted oxide condenses in the reflux condenser and flows back into the reactor «without liquid flooding». After feeding of ethylene (propylene) oxide, the reaction mixture is further heated and then cooled to room temperature.

The catalyst is neutralized with a calculated amount of sulfuric acid and the resulting mass is filtered. 


\section{Method of estirification of phthalic anhydride}

In a three-necked flask equipped with a Dean-Stark trap cooler thermometer and a mechanical stirrer phthalic anhydride, oxyalkylated alcohol and catalyst, $\mathrm{p}$-toluenesulfonic acid (PTSA) or tetrabutoxytitanium are placed. The reaction is carried out until the estimated amount of water is formed in the trap. After completion of the reaction, the catalyst is hydrolyzed with water and the product of esterification is filtered off. In case of using PTSA, an inert gas - carbon dioxide or nitrogen - is bubbled through the reaction mixture to facilitate the removal of water that forms.

The general scheme for obtaining oxyalkylated phthalates of alcohols has the following form:

\section{Table 1}

Optimum conditions for obtaining chemical additives

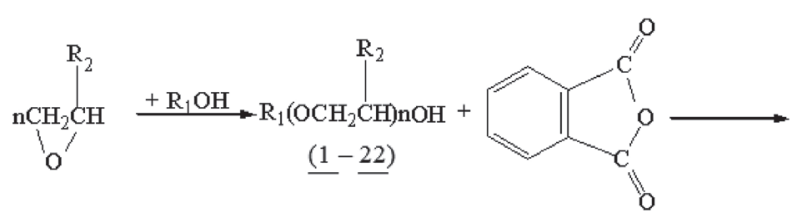

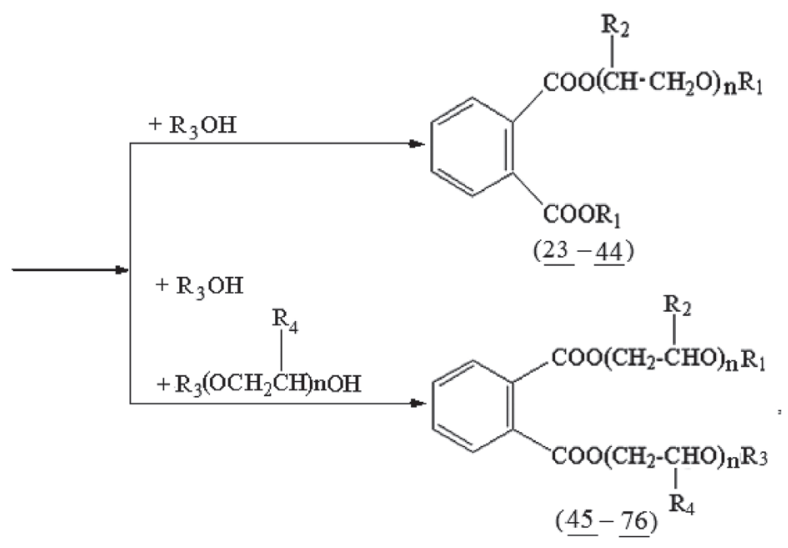

\begin{tabular}{|c|c|c|c|c|}
\hline Synthesized compounds & $\begin{array}{l}\text { Molecular } r \\
\text { of reagent }\end{array}$ & & $\begin{array}{c}\text { Tempera- } \\
\text { ture, }{ }^{\circ} \mathrm{C}\end{array}$ & Note \\
\hline $\begin{array}{l}\mathrm{R}_{2}^{\mathrm{R}_{2}} \\
\mathrm{R}_{1}\left(\mathrm{OCH}_{2} \mathrm{CH}\right) \mathrm{nOH}, \\
\text { where } \mathrm{R}_{1}=\mathrm{C}_{4} \mathrm{H}_{9} ; \mathrm{R}_{2}=\mathrm{H}(1-4), \mathrm{CH}_{3}(5-8) ; \\
\mathrm{R}_{1}=\mathrm{C}_{8} \mathrm{H}_{17} ; \mathrm{R}_{2}=\mathrm{H}(9-12), \mathrm{CH}_{3}(13-16) ; \\
\mathrm{R}_{1}=\mathrm{C}_{6} \mathrm{H}_{5} ; \mathrm{R}_{2}=\mathrm{H}(17), \mathrm{CH}_{3}(18) ; \\
\mathrm{R}_{1}=\mathrm{C}_{6} \mathrm{H}_{5} \mathrm{CH}_{2} ; \mathrm{R}_{2}=\mathrm{CH}_{3}(19-22)\end{array}$ & $\begin{array}{l}\text { Alcohol: ethy- } \\
\text { lene (propylene) } \\
\text { oxide }\end{array}$ & $1: 1-3$ & $110-180$ & $\begin{array}{l}\text { amount of catalyst } \\
0,5-3 \% \text { (mass. from } \\
\text { loading) }\end{array}$ \\
\hline $\begin{array}{l}\text { where } \mathrm{R}_{1}=\mathrm{C}_{4} \mathrm{H}_{9} ; \mathrm{R}_{3}=\mathrm{C}_{4} \mathrm{H}_{9} ; \mathrm{R} 2=\mathrm{H}(23-26), \mathrm{CH}_{3}(27-30) ; \\
\mathrm{R}_{1}=\mathrm{C}_{8} \mathrm{H}_{11} ; \mathrm{R}_{3}=\mathrm{C}_{8} \mathrm{H}_{11} ; \mathrm{R}_{2}=\mathrm{H}(31-34), \mathrm{CH}_{3}(35-38) ; \\
\mathrm{R}_{1}=\mathrm{C}_{6} \mathrm{H}_{5} \mathrm{CH}_{2} ; \mathrm{R}_{3}=\mathrm{C}_{6} \mathrm{H}_{5} \mathrm{CH}_{2} ; \mathrm{R}_{2}=\mathrm{CH}_{3}(39-42) ; \\
\mathrm{R}_{1}=\mathrm{C}_{8} \mathrm{H}_{17} ; \mathrm{R}_{3}=\mathrm{C}_{6} \mathrm{H}_{5} ; \mathrm{R}_{2}=\mathrm{H}(43), \mathrm{CH}_{3}(44) .\end{array}$ & \begin{tabular}{|l|} 
Phthalic \\
anhydride: \\
oxyalkylated \\
alcohol
\end{tabular} & $1: 1,5$ & $110-140$ & \begin{tabular}{|l} 
amount of catalyst \\
$0,1-2 \%$ (mass. from \\
loading) + activated \\
carbon in quantity $1 \%$ \\
(mass. from wight of \\
loaded components)
\end{tabular} \\
\hline $\begin{array}{l}\text { where } \mathrm{R}_{1}=\mathrm{C}_{4} \mathrm{H}_{9} ; \mathrm{R}_{3}=\mathrm{C}_{4} \mathrm{H}_{9} ; \mathrm{R}_{2}=\mathrm{H}(45-48), \mathrm{R}_{4}=\mathrm{CH}_{3}(49-52) ; \\
\mathrm{R}_{1}=\mathrm{C}_{8} \mathrm{H}_{17} ; \mathrm{R}_{3}=\mathrm{C}_{8} \mathrm{H}_{17} ; \mathrm{R}_{2}=\mathrm{H}(53-56), \mathrm{R}_{4}=\mathrm{CH}_{3}(57-60) ; \\
\mathrm{R}_{1}=\mathrm{C}_{6} \mathrm{H}_{5} ; \mathrm{R}_{3}=\mathrm{C}_{4} \mathrm{H}_{9} ; \mathrm{R}_{2}=\mathrm{H} ; \mathrm{R}_{4}=\mathrm{H}(61-64) ; \\
\mathrm{R}_{1}=\mathrm{C}_{6} \mathrm{H}_{5} ; \mathrm{R}_{3}=\mathrm{C}_{4} \mathrm{H}_{9} ; \mathrm{R}_{2}=\mathrm{CH}_{3} ; \mathrm{R}_{4}=\mathrm{CH}_{3}(65-68) ; \\
\mathrm{R}_{1}=\mathrm{C}_{6} \mathrm{H}_{5} ; \mathrm{R}_{3}=\mathrm{C}_{4} \mathrm{H}_{3} ; \mathrm{R}_{2}=\mathrm{H} ; \mathrm{R}_{4}=\mathrm{CH}_{3}(69-72) ; \\
\mathrm{R}_{1}=\mathrm{C}_{6} \mathrm{H}_{5} ; \mathrm{R}_{3}=\mathrm{C}_{4} \mathrm{H}_{9} ; \mathrm{R}_{2}=\mathrm{CH}_{3} ; \mathrm{R}_{4}=\mathrm{H}(73-76)\end{array}$ & \begin{tabular}{|l|} 
Phthalic \\
anhydride: \\
oxyalkylated \\
alcohol
\end{tabular} & $1: 2,5$ & $120-180$ & $\begin{array}{l}\text { amount of catalyst } \\
0,1-2 \% \text { (mass. from } \\
\text { loading) + activated } \\
\text { carbon in quantity } 1 \% \\
\text { (mass. from wight of } \\
\text { loaded components) }\end{array}$ \\
\hline
\end{tabular}


where $\mathrm{R}_{1}=\mathrm{C}_{4} \mathrm{H}_{9} ; \mathrm{C}_{8} \mathrm{H}_{17} ; \mathrm{C}_{6} \mathrm{H}_{5} ; \mathrm{C}_{6} \mathrm{H}_{5} \mathrm{CH}_{2} ; \mathrm{R}_{2}=\mathrm{H}$; $\mathrm{CH}_{3} ; \mathrm{R}_{3}=\mathrm{C}_{4} \mathrm{H}_{9} ; \mathrm{C}_{8} \mathrm{H}_{17} ; \mathrm{C}_{6} \mathrm{H}_{5} ; \mathrm{C}_{6} \mathrm{H}_{5} \mathrm{CH}_{2} ; \mathrm{R}_{4}=\mathrm{H} ; \mathrm{CH}_{3}$.

The conditions for obtaining plasticizers with a yield of more than $80 \%$ are given in the Table 1 .

Physic-chemical properties of synthesized compounds are given in Tables 2, 3 .

From Table 2 it can be seen that with an increase in the degree of oxyalkylation, the density and refractive index increase.

From the obtained results it can be seen that with an increase in the degree of oxyalkylation, the refractive index of the esters decreases and the density increases.
Physical and chemical characteristics of plasticizers were analyzed according to GOST 8728-88.

\section{RESULTS AND DISCUSSION}

To determine the efficiency of developed plasticizers the changing of Shor A hardness from the concentration of plasticizer were studied (plasticizer:PVC-1:100). On the base of calculation of quantitative substitution factor (SF), which determines the required amount of phthalates of oxyalkylated alcohols compared to DOP and provides the necessary hardness of flexible PVC under room

\section{Table 2}

Physic-chemical properties of oxyalkylated alcohols

\begin{tabular}{|c|c|c|c|c|c|}
\hline № compound & $\mathbf{n}$ & $\mathrm{d}^{20}{ }_{4}$ & $\mathrm{n}^{20}{ }_{\mathrm{D}}$ & $\begin{array}{c}\text { Ester number, mg } \\
\mathrm{KOH} / \mathrm{g}\end{array}$ & Molar mass, found \\
\hline \multicolumn{6}{|c|}{ Oxyethylated butanols } \\
\hline 1 & 1,5 & 0,9745 & 1,4285 & 790 & 142 \\
\hline 2 & 2,0 & 0,9842 & 1,4333 & 681 & 165 \\
\hline 3 & 2,2 & 0,9875 & 1,4351 & 644 & 173 \\
\hline 4 & 2,4 & 0,9895 & 1,4369 & 615 & 182 \\
\hline \multicolumn{6}{|c|}{ Oxypropylated Butanols } \\
\hline 5 & 1,5 & 0,9130 & 1,4274 & 693 & 162 \\
\hline 6 & 2,0 & 0,9224 & 1,4289 & 586 & 192 \\
\hline 7 & 2,2 & 0,9253 & 1,4296 & 552 & 203 \\
\hline 8 & 2,4 & 0,9287 & 1,4303 & 522 & 215 \\
\hline \multicolumn{6}{|c|}{ Oxyethylated 2-ethylhexanols } \\
\hline 9 & 1,5 & 0,9141 & 1,4325 & 568 & 197 \\
\hline 10 & 2,0 & 0,9240 & 1,4490 & 510 & 220 \\
\hline 11 & 2,4 & 0,9309 & 1,4580 & 471 & 238 \\
\hline 12 & 3,0 & 0,9382 & 1,4696 & 422 & 265 \\
\hline \multicolumn{6}{|c|}{ Oxypropylated 2-ethylhexanols } \\
\hline 13 & 1,3 & 0,8757 & 1,4329 & 538 & 208 \\
\hline 14 & 1,9 & 0,8787 & 1,4342 & 461 & 243 \\
\hline 15 & 2,3 & 0,8841 & 1,4358 & 423 & 265 \\
\hline 16 & 2,7 & 0,8911 & 1,4379 & 386 & 290 \\
\hline \multicolumn{6}{|c|}{ Oxyethylated phenol } \\
\hline 17 & 1,0 & 1,1007 & 1,5314 & 789 & 142 \\
\hline \multicolumn{6}{|c|}{ Oxypropylated phenol } \\
\hline 18 & 2,1 & 1,0773 & 1,5338 & 514 & 218 \\
\hline \multicolumn{6}{|c|}{ Oxypropylated phenylcarbinols } \\
\hline 19 & 1,1 & 1,0114 & 1,5216 & 640 & 175 \\
\hline 20 & 1,7 & 1,0136 & 1,5259 & 533 & 210 \\
\hline 21 & 2,4 & 1,0162 & 1,5298 & 448 & 250 \\
\hline 22 & 2,7 & 1,0176 & 1,5318 & 416 & 269 \\
\hline
\end{tabular}


Nanotechnologies in Construction: A Scientific Internet-Journal

Table 3

Physico-chemical properties of oxyalkylated alcohols phthalates

\begin{tabular}{|c|c|c|c|c|c|c|}
\hline № compound & n & $\mathrm{n}^{20}{ }_{\mathrm{D}}$ & $\mathrm{d}^{20}{ }_{4}$ & $\begin{array}{l}\text { Acid number, } \\
\mathrm{mg} \mathrm{KOH} / \mathrm{g}\end{array}$ & $\begin{array}{c}\text { Ester number, } \\
\mathrm{mg} \mathrm{KOH} / \mathrm{g}\end{array}$ & $\begin{array}{l}\text { Molar mass, } \\
\text { found }\end{array}$ \\
\hline 1 & 2 & 3 & 4 & 5 & 6 & 7 \\
\hline \multicolumn{7}{|c|}{ Butylbutoxyethyl phthalates } \\
\hline 23 & 1,5 & 1,4889 & 1,0559 & 0,10 & 321 & 349 \\
\hline 24 & 2,0 & 1,4883 & 1,0581 & 0,10 & 302 & 371 \\
\hline 25 & 2,2 & 1,4879 & 1,0601 & 0,10 & 295 & 380 \\
\hline 26 & 2,4 & 1,4874 & 1,0615 & 0,10 & 288 & 389 \\
\hline \multicolumn{7}{|c|}{ Butylbutoxypropyl phthalates } \\
\hline 27 & 1,5 & 1,4814 & 1,0237 & 0,05 & 303 & 370 \\
\hline 28 & 2,0 & 1,4796 & 1,0298 & 0,08 & 281 & 399 \\
\hline 29 & 2,2 & 1,4781 & 1,0307 & 0,08 & 272 & 412 \\
\hline 30 & 2,4 & 1,4775 & 1,0324 & 0,10 & 265 & 422 \\
\hline \multicolumn{7}{|c|}{ Octyloctoxyethyl phthalates } \\
\hline 31 & 1,5 & 1,4812 & 0,9875 & 0,10 & 242 & 463 \\
\hline 32 & 2,0 & 1,4790 & 0,9930 & 0,10 & 231 & 485 \\
\hline 33 & 2,4 & 1,4768 & 0,9986 & 0,10 & 222 & 505 \\
\hline 34 & 3,0 & 1,4748 & 1,0097 & 0,10 & 213 & 526 \\
\hline \multicolumn{7}{|c|}{ Octyloxytoxypropyl phthalates } \\
\hline 35 & 1,3 & 1,4775 & 0,9681 & 0,20 & 237 & 473 \\
\hline 36 & 1,9 & 1,4745 & 0,9738 & 0,20 & 220 & 509 \\
\hline 37 & 2,3 & 1,4733 & 0,9776 & 0,20 & 210 & 533 \\
\hline 38 & 2,7 & 1,4719 & 0,9813 & 0,20 & 201 & 557 \\
\hline \multicolumn{7}{|c|}{ Benzylbenzoxypropyl phthalates } \\
\hline 39 & 1,1 & 1,5189 & 1,1075 & 0,20 & 271 & 413 \\
\hline 40 & 1,7 & 1,5178 & 1,1098 & 0,15 & 250 & 448 \\
\hline 41 & 2,4 & 1,5168 & 1,1122 & 0,20 & 229 & 489 \\
\hline 42 & 2,7 & 1,5163 & 1,1136 & 1,15 & 222 & 505 \\
\hline \multicolumn{7}{|c|}{ Octylphenoxyethyl phthalates } \\
\hline 43 & 1,0 & 1,4863 & 1,0214 & 0,10 & 313 & 358 \\
\hline \multicolumn{7}{|c|}{ Octylphenoxypropyl phthalates } \\
\hline 44 & 2,1 & 1,4756 & 1,0098 & 0,10 & 232 & 481 \\
\hline \multicolumn{7}{|c|}{ Dibutoxyethyl phthalates } \\
\hline 45 & 1,5 & 1,0648 & 1,4855 & 0,20 & 271 & 413 \\
\hline 46 & 2,0 & 1,0757 & 1,4816 & 0,10 & 243 & 461 \\
\hline 47 & 2,2 & 1,0837 & 1,4755 & 0,10 & 236 & 475 \\
\hline 48 & 2,4 & 1,0863 & 1,4742 & 0,20 & 226 & 496 \\
\hline \multicolumn{7}{|c|}{ Dibutoxypropyl phthalates } \\
\hline 49 & 1,5 & 1,0286 & 1,4779 & 0,30 & 246 & 456 \\
\hline 50 & 2,0 & 1,0296 & 1,4751 & 0,40 & 217 & 515 \\
\hline 51 & 2,2 & 1,0299 & 1,4745 & 0,30 & 207 & 541 \\
\hline 52 & 2,4 & 1,0304 & 1,4739 & 0,30 & 200 & 561 \\
\hline
\end{tabular}


Nanotechnologies in Construction: A Scientific Internet-Journal

Table 3

\begin{tabular}{|c|c|c|c|c|c|c|}
\hline 1 & 2 & 3 & 4 & 5 & 6 & 7 \\
\hline \multicolumn{7}{|c|}{ Dioctoxyethyl phthalates } \\
\hline 53 & 1,5 & 0,9887 & 1,4797 & 0,30 & 211 & 531 \\
\hline 54 & 2,0 & 0,9982 & 1,4783 & 0,30 & 195 & 574 \\
\hline 55 & 2,4 & 1,0047 & 1,4772 & 0,38 & 183 & 612 \\
\hline 56 & 3,0 & 1,0132 & 1,4754 & 0,30 & 168 & 667 \\
\hline \multicolumn{7}{|c|}{ Dioctoxypropyl phthalates } \\
\hline 57 & 1,3 & 0,9642 & 1,4619 & 0,30 & 203 & 552 \\
\hline 58 & 1,9 & 0,9978 & 1,4607 & 0,40 & 180 & 622 \\
\hline 59 & 2,3 & 1,0253 & 1,4599 & 0,30 & 166 & 675 \\
\hline 60 & 2,7 & 1,0429 & 1,4594 & 0,50 & 155 & 722 \\
\hline \multicolumn{7}{|c|}{ Butoxyethylphenoxyethyl phthalate } \\
\hline 61 & 1,5 & 1,5190 & 1,1054 & 0,20 & 271 & 415 \\
\hline 62 & 2,0 & 1,5183 & 1,1081 & 0,20 & 257 & 436 \\
\hline 63 & 2,2 & 1,5180 & 1,1110 & 0,20 & 252 & 444 \\
\hline 64 & 2,4 & 1,5176 & 1,1119 & 0,20 & 247 & 454 \\
\hline \multicolumn{7}{|c|}{ Butoxypropylphenoxypropyl phthalate } \\
\hline 65 & 1,5 & 1,5184 & 1,1034 & 0,20 & 201 & 558 \\
\hline 66 & 2,0 & 1,5178 & 1,1062 & 0,20 & 211 & 514 \\
\hline 67 & 2,2 & 1,5175 & 1,1078 & 0,20 & 214 & 524 \\
\hline 68 & 2,4 & 1,5172 & 1,1091 & 0,20 & 218 & 531 \\
\hline \multicolumn{7}{|c|}{ Butoxyethylphenoxypropyl phthalate } \\
\hline 69 & 1,5 & 1,5184 & 1,1034 & 0,20 & 201 & 558 \\
\hline 70 & 2,0 & 1,5178 & 1,1062 & 0,20 & 211 & 514 \\
\hline 71 & 2,2 & 1,5175 & 1,1078 & 0,20 & 214 & 524 \\
\hline 72 & 2,4 & 1,5172 & 1,1091 & 0,20 & 218 & 531 \\
\hline \multicolumn{7}{|c|}{ Butoxypropylphenoxyethyl phthalates } \\
\hline 73 & 1,5 & 1,5187 & 1,1014 & 0,20 & 257 & 435 \\
\hline 74 & 2,0 & 1,5183 & 1,1042 & 0,20 & 241 & 464 \\
\hline 75 & 2,2 & 1,5178 & 1,1060 & 0,20 & 235 & 476 \\
\hline 76 & 2,4 & 1,5174 & 1,1074 & 0,20 & 230 & 486 \\
\hline
\end{tabular}

conditions, it was found that compounds $24,29,31,35$, $39,44,47,50,53,57,61,62,67$ are very similar to DOP in plasticizing efficiency. These plasticizers are characterized by high-solvency of PVC and a low tendency to migrate from plasticized film, because, as is known, the migration of plasticizer from a material plays a big part in maintaining the properties of PVC materials during operation for a long time [1]. Analysis of plasticizing properties showed that obtained PVC films do not possess visible signs of migration of plasticizer and possess good elastic properties.

Selected samples were tested in some PVC compositions for construction purposes.
Testing of plasticizers in the formulation of cable plastic brand $\mathrm{O}-40$ rec. $\mathrm{OM}-40$ (black)

Samples of cable plastic brand O-40 rec. OM- 40 (black) was analyzed according to GOST 5960-72 rev. 1-9 «Polyvinyl chloride plasticate for insulation and protective sheaths of wires and cables». Results of testing are shown in Table 4.

Represented data in the table show that the main characteristics - breaking strength, elongation at break, shatter point of obtained cable plastics are not inferior to industrial samples, and such indicators as «Weight loss at $160^{\circ} \mathrm{C}$ » and «Water absorption» are much lower 


\section{Table 4}

Results of testing plasticizers in the formulation of cable plastic brand O-40 rec. OM-40 (black)

\begin{tabular}{|c|c|c|c|c|c|c|}
\hline \multirow{5}{*}{ Characteristics } & \multicolumn{6}{|c|}{ Plasticizer } \\
\hline & \multirow{4}{*}{$\begin{array}{c}\text { Norms according } \\
\text { to GOST 5960-72 } \\
\text { rev. } 1-9 \\
\left(1^{\text {st }} \text { class }\right)\end{array}$} & \multirow{4}{*}{$\begin{array}{l}\text { Control } \\
\text { sample }\end{array}$} & \multicolumn{4}{|c|}{ № compound } \\
\hline & & & 47 & 50 & 24 & 29 \\
\hline & & & \multicolumn{4}{|c|}{ № sample } \\
\hline & & & I & II & III & IV \\
\hline $\begin{array}{l}\text { Specific insulation resistance } \\
\text { at } 20^{\circ} \mathrm{C}, \mathrm{Ohm} \cdot \mathrm{sm}\end{array}$ & $\begin{array}{l}\text { No less than } \\
1 \cdot 10^{10}\end{array}$ & $9,0 \cdot 10^{12}$ & $6,3 \cdot 10^{12}$ & $4,5 \cdot 10^{12}$ & $7,5 \cdot 10^{12}$ & $6,0 \cdot 10^{12}$ \\
\hline Breaking strength, $\mathrm{kg} / \mathrm{cm}^{2}$ & No less than 110 & 147 & 140 & 142 & 144 & 140 \\
\hline Elongation at break, $\%$ & No less than 280 & 385 & 328 & 345 & 336 & 276 \\
\hline Shatter point, ${ }^{\circ} \mathrm{C}$ & Not above -40 & \multicolumn{5}{|c|}{ Stand the test } \\
\hline $\begin{array}{l}\text { Weight loss at } 160^{\circ} \mathrm{C} \text {, } \\
\text { within } 6 \mathrm{~h} ., \%\end{array}$ & No more than 3,0 & 2,2 & 2,0 & 1,7 & 1,8 & 1,6 \\
\hline $\begin{array}{l}\text { Hardness, } \mathrm{kg} / \mathrm{cm}^{2}, \\
\text { at } 20^{\circ} \mathrm{C} \\
\text { at } 70^{\circ} \mathrm{C}\end{array}$ & $\begin{array}{l}\text { No less than } \\
\quad 9-20 \\
6-12\end{array}$ & $\begin{array}{l}12,5 \\
7,3\end{array}$ & $\begin{array}{l}11,3 \\
7,2\end{array}$ & $\begin{array}{c}11,8 \\
7,1\end{array}$ & $\begin{array}{l}12,1 \\
7,3\end{array}$ & $\begin{array}{l}11,9 \\
7,4\end{array}$ \\
\hline Water absorption, $\%$ & No more than 0,45 & 0,080 & 0,040 & 0,052 & 0,350 & 0,053 \\
\hline Softening temperature, ${ }^{\circ} \mathrm{C}$ & $170 \pm 10$ & 171 & 171 & 172 & 169 & 171 \\
\hline Density, $\mathrm{g} / \mathrm{cm}^{3}$ & No more than 1,4 & 1,38 & 1,39 & 1,38 & 1,39 & 1,38 \\
\hline \multicolumn{7}{|c|}{ Technological properties } \\
\hline $\begin{array}{l}\text { Thermostability at } 180^{\circ} \mathrm{C}, \\
\text { min }\end{array}$ & GOST 14041-91 & 2 h. 15 min. & 2 h. 16 min. & 2 h. 24 min. & $2 \mathrm{~h} .35 \mathrm{~min}$. & $2 \mathrm{~h} .12 \mathrm{~min}$. \\
\hline $\begin{array}{l}\text { Melt flow rate, } \mathrm{g} / 10 \mathrm{~min} \\
\mathrm{~T}=190^{\circ} \mathrm{C}, \mathrm{P}=10 \mathrm{~kg} / \mathrm{cm}^{2}\end{array}$ & GOST 11645-73 & 103,3 & 106,3 & 102,0 & 98,7 & 102,4 \\
\hline
\end{tabular}

Table 5

Results of testing PVC adhesive tape

\begin{tabular}{|c|c|c|c|c|c|c|c|c|c|c|c|}
\hline \multirow{5}{*}{ Characteristics } & \multicolumn{11}{|c|}{ Plasticizer } \\
\hline & \multirow{4}{*}{$\begin{array}{c}\text { Norms according } \\
\text { to TS 2245-001- } \\
00203312-2003\end{array}$} & \multirow{4}{*}{$\begin{array}{c}\text { Con- } \\
\text { trol } \\
\text { sam- } \\
\text { ple }\end{array}$} & \multicolumn{9}{|c|}{ № compound } \\
\hline & & & 53 & 57 & 31 & 35 & 62 & 61 & 67 & 39 & 44 \\
\hline & & & \multicolumn{9}{|c|}{ № sample } \\
\hline & & & $\mathbf{V}$ & VI & VII & VIII & IX & $\mathbf{X}$ & XI & XII & XIII \\
\hline $\begin{array}{l}\text { Breaking strength, } \\
\mathrm{kg} / \mathrm{cm}^{2}\end{array}$ & $\begin{array}{l}\text { No less } \\
\text { than } 50\end{array}$ & 73 & 65 & 71 & 69 & 73 & 65 & 71 & 69 & 70 & 72 \\
\hline Tensile strain, $\%$ & No less than 280 & 277 & 258 & 262 & 281 & 276 & 258 & 262 & 281 & 276 & 275 \\
\hline Shatter point, ${ }^{\circ} \mathrm{C}$ & Not above -30 & & & & & Stand $\mathrm{t}$ & the test & & & & \\
\hline \multicolumn{12}{|c|}{ Technological properties } \\
\hline $\begin{array}{l}\text { Thermostability } \\
\text { at } 170^{\circ} \mathrm{C} \text {, min. }\end{array}$ & GOST 14041-91 & $\begin{array}{l}2 \text { h. } 07 \\
\text { min. }\end{array}$ & $\begin{array}{l}2 \text { h. } 05 \\
\text { min. }\end{array}$ & $\begin{array}{l}2 \mathrm{~h} .15 \\
\text { min. }\end{array}$ & \begin{tabular}{|c|}
2 h. 59 \\
min.
\end{tabular} & \begin{tabular}{|c|}
$2 \mathrm{~h} .06$ \\
min.
\end{tabular} & $\begin{array}{l}2 \text { h. } 11 \\
\text { min. }\end{array}$ & \begin{tabular}{|c|}
$2 \mathrm{~h} .08$ \\
min.
\end{tabular} & \begin{tabular}{|c|}
$2 \mathrm{~h} .27$ \\
min.
\end{tabular} & \begin{tabular}{|c|}
2 h. 29 \\
min.
\end{tabular} & $\begin{array}{l}2 \mathrm{~h} .06 \\
\text { min. }\end{array}$ \\
\hline $\begin{array}{l}\text { Melt flow rate, } \\
\text { at } \mathrm{T}=180^{\circ} \mathrm{C}, \\
\mathrm{H}=16,6 \mathrm{kgf}, \\
\mathrm{g} / 10 \mathrm{~min} .\end{array}$ & GOST 11645-73 & 10,5 & 14,8 & 12,5 & 14,2 & 12,8 & 14,8 & 12,5 & 14,2 & 13,8 & 14,1 \\
\hline
\end{tabular}




\section{DEVELOPMENT OF NEW POLYMER MATERIALS • РАЗРАБОTКА НОВЫХ ПОЛИМЕРНЫХ МАTЕРИАЛОВ}

specifically when using butylbutoxypropylphthalate and dibutoxyethylphthalate and dibutoxypropylphthalate.

\section{Testing of plasticizers in the formulation of PVC adhesive tape}

The obtained samples of PVC adhesive tape were analyzed according to TS 2245-001-00203312-2003 (PVC adhesive tape). Results of analysis are shown in Table 5.

According to the data from the table, PVC adhesive tape meets the technical requirements. It is noted that using the ester compounds obtained by us improves the indicators, specifically: «Breaking strength», «Tensile strain», «Shatter temperature» and «Thermostability». Almost in all cases these samples provide technological and operational characteristics above the level of the DOP serial plasticizer.

\section{Testing of plasticizers in multilayer linoleum}

For the manufacture of multilayer baseless linoleum, polyvinyl chloride films were preliminarily obtained: the upper transparent, middle and lower layers, which were analyzed according to the GTP 00203312-100-2006. Results of analysis are shown in Table 6 .

The data from the Table 6 show that replacement of dioctyl phthalate with oxyalkylated alcohols phthalates makes it possible to obtain PVC films with high thermal stability and improved melt flow. According to the test results, in all cases of using the prototypes, the main technological characteristics were noticeably better, that indicates facilitated processing of the PVC-compositions. It can be seen that the indicators «Thermalstability time» and «Melt Flow Rate» decrease

Table 6

Testing results of plasticizers in PVC formulations in the upper, middle and lower layers of linoleum

\begin{tabular}{|c|c|c|c|c|c|c|c|c|c|}
\hline \multirow{5}{*}{ Characteristics } & \multicolumn{9}{|c|}{ Plasticicer } \\
\hline & \multirow{4}{*}{$\begin{array}{c}\text { Norms according to } \\
\text { CSS 00203312-100-2006 }\end{array}$} & \multicolumn{8}{|c|}{ № compound } \\
\hline & & 47 & 50 & 24 & 29 & 53 & 57 & 31 & 35 \\
\hline & & \multicolumn{8}{|c|}{ № sample } \\
\hline & & I & II & III & VI & $\mathbf{V}$ & VI & VII & VIII \\
\hline 1 & 2 & 3 & 4 & 5 & 6 & 7 & 8 & 9 & 10 \\
\hline \multicolumn{10}{|c|}{$\begin{array}{l}\text { Industrial formulation of the upper layer of linoleum } \\
\text { (Plasticized PVC plasticate transparent with an embossed surface and without embossing) }\end{array}$} \\
\hline $\begin{array}{l}\text { Longitudinal strength, } \mathrm{kg} / \mathrm{cm}^{2} \\
\text { along } \\
\text { across }\end{array}$ & $\begin{array}{c}\text { No less than } \\
175 \\
175 \\
\end{array}$ & $\begin{array}{l}270 \\
277 \\
\end{array}$ & $\begin{array}{l}284 \\
258 \\
\end{array}$ & $\begin{array}{l}282 \\
259 \\
\end{array}$ & $\begin{array}{l}287 \\
232\end{array}$ & $\begin{array}{l}279 \\
241 \\
\end{array}$ & $\begin{array}{l}294 \\
221 \\
\end{array}$ & $\begin{array}{l}285 \\
254 \\
\end{array}$ & $\begin{array}{l}290 \\
227\end{array}$ \\
\hline $\begin{array}{l}\text { Breaking elongation, \% } \\
\text { along } \\
\text { across }\end{array}$ & $\begin{array}{c}\text { No less than } \\
100 \\
100\end{array}$ & $\begin{array}{l}221 \\
293\end{array}$ & $\begin{array}{l}249 \\
258\end{array}$ & $\begin{array}{l}256 \\
281\end{array}$ & $\begin{array}{l}275 \\
269\end{array}$ & $\begin{array}{l}297 \\
253\end{array}$ & $\begin{array}{l}318 \\
301\end{array}$ & $\begin{array}{l}249 \\
266\end{array}$ & $\begin{array}{l}263 \\
253\end{array}$ \\
\hline Change in linear dimensions , $\%$ & No more than 3,0 & 1,4 & 1,2 & 1,5 & 1,4 & 2,0 & 1,3 & 1,7 & 1,8 \\
\hline \multicolumn{10}{|c|}{ Technological properties } \\
\hline Thermostability at $180^{\circ} \mathrm{C}$, min & $\begin{array}{l}\text { Control with DOP } \\
\text { 1h. } 45 \text { min. }\end{array}$ & $\begin{array}{c}\text { 1h. } \\
38 \\
\text { min. }\end{array}$ & $\begin{array}{c}\mathrm{h} . \\
51 \\
\min .\end{array}$ & $\begin{array}{c}\mathrm{hh} . \\
41 \\
\min .\end{array}$ & $\begin{array}{c}\mathrm{h} . \\
43 \\
\min .\end{array}$ & $\begin{array}{c}1 \mathrm{~h} . \\
35 \\
\min .\end{array}$ & $\begin{array}{c}1 \mathrm{~h} . \\
48 \\
\min .\end{array}$ & $\begin{array}{c}1 \mathrm{~h} . \\
37 \\
\min .\end{array}$ & $\begin{array}{c}1 \mathrm{~h} . \\
40 \\
\min .\end{array}$ \\
\hline $\begin{array}{l}\text { Melt flow rate, } \mathrm{g} / 10 \mathrm{~min} \\
\mathrm{~T}=170^{\circ} \mathrm{C}, \mathrm{P}=16,6 \mathrm{kgf}\end{array}$ & 7,1 & 8,5 & 9,3 & 8,4 & 8,6 & 7,5 & 8,3 & 8,9 & 9,1 \\
\hline \multicolumn{10}{|c|}{ Industrial formulation of the middle layer of linoleum (Plasticized PVC plasticate filled with natural color) } \\
\hline $\begin{array}{l}\text { Longitudinal strength, } \mathrm{kg} / \mathrm{cm}^{2} \\
\text { along } \\
\text { across }\end{array}$ & $\begin{array}{c}\text { No less than } \\
100 \\
100 \\
\end{array}$ & $\begin{array}{l}149 \\
125\end{array}$ & $\begin{array}{l}152 \\
136 \\
\end{array}$ & $\begin{array}{l}168 \\
130 \\
\end{array}$ & $\begin{array}{l}162 \\
114 \\
\end{array}$ & $\begin{array}{l}138 \\
105 \\
\end{array}$ & $\begin{array}{l}143 \\
120 \\
\end{array}$ & $\begin{array}{l}163 \\
140\end{array}$ & $\begin{array}{l}142 \\
124\end{array}$ \\
\hline $\begin{array}{l}\text { Breaking elongation, \% } \\
\text { along } \\
\text { across }\end{array}$ & $\begin{array}{c}\text { No less than } \\
100 \\
100\end{array}$ & $\begin{array}{l}189 \\
242\end{array}$ & $\begin{array}{l}198 \\
232\end{array}$ & $\begin{array}{l}252 \\
180\end{array}$ & $\begin{array}{l}243 \\
192\end{array}$ & $\begin{array}{l}190 \\
178\end{array}$ & $\begin{array}{l}200 \\
204\end{array}$ & $\begin{array}{l}223 \\
217\end{array}$ & $\begin{array}{l}209 \\
240\end{array}$ \\
\hline Change in linear dimensions, $\%$ & No more than 3,0 & 1,6 & 1,3 & 1,0 & 1,2 & 1,5 & 1,0 & 1,3 & 1,4 \\
\hline \multicolumn{10}{|c|}{ Technological properties } \\
\hline Thermostability at $180^{\circ} \mathrm{C}$, min & Control with DOP 37 min. & $\begin{array}{c}31 \\
\min .\end{array}$ & $\begin{array}{c}32 \\
\min \end{array}$ & $\begin{array}{c}37 \\
\text { min. }\end{array}$ & $\begin{array}{c}34 \\
\text { min. }\end{array}$ & $\begin{array}{c}30 \\
\text { min. }\end{array}$ & $\begin{array}{l}35 \\
\text { min. }\end{array}$ & $\begin{array}{c}39 \\
\text { min. }\end{array}$ & $\begin{array}{c}33 \\
\text { min. }\end{array}$ \\
\hline $\begin{array}{l}\text { Melt flow rate, } g / 10 \mathrm{~min} \\
\mathrm{~T}=170^{\circ} \mathrm{C}, \mathrm{P}=16,6 \mathrm{kgf}\end{array}$ & 8,1 & 9,5 & 9,7 & 10,5 & 9,9 & 8,4 & 8,9 & 10,4 & 9,2 \\
\hline
\end{tabular}


Table 6

\begin{tabular}{|c|c|c|c|c|c|c|c|c|c|}
\hline 1 & 2 & 3 & 4 & 5 & 6 & 7 & 8 & 9 & 10 \\
\hline \multicolumn{10}{|c|}{ Industrial formulation of the lower layer of linoleum (Plasticized PVC plasticate filled) } \\
\hline $\begin{array}{l}\text { Longitudinal strength, } \mathrm{kg} / \mathrm{cm}^{2} \\
\text { along } \\
\text { across }\end{array}$ & $\begin{array}{c}\text { No less than } \\
75 \\
75\end{array}$ & $\begin{array}{l}116 \\
80\end{array}$ & $\begin{array}{c}127 \\
91\end{array}$ & $\begin{array}{l}133 \\
116\end{array}$ & $\begin{array}{l}136 \\
118\end{array}$ & $\begin{array}{l}117 \\
85\end{array}$ & $\begin{array}{l}133 \\
103\end{array}$ & $\begin{array}{l}129 \\
99\end{array}$ & $\begin{array}{l}131 \\
100\end{array}$ \\
\hline $\begin{array}{l}\text { Breaking elongation, \% } \\
\text { along } \\
\text { across }\end{array}$ & $\begin{array}{l}\text { No less than } \\
100 \\
100\end{array}$ & $\begin{array}{l}211 \\
151\end{array}$ & $\begin{array}{l}233 \\
208\end{array}$ & $\begin{array}{l}209 \\
152\end{array}$ & $\begin{array}{l}223 \\
163\end{array}$ & $\begin{array}{l}208 \\
157\end{array}$ & $\begin{array}{l}231 \\
219\end{array}$ & $\begin{array}{l}245 \\
252\end{array}$ & $\begin{array}{l}256 \\
245\end{array}$ \\
\hline Change in linear dimensions, $\%$ & No more than 3,0 & 0,9 & 0,5 & 0,5 & 0,4 & 0,9 & 0,4 & 0,6 & 0,7 \\
\hline \multicolumn{10}{|c|}{ Technological properties } \\
\hline Thermostability at $180^{\circ} \mathrm{C}$, min & Control with DOP 28 min. & $\begin{array}{c}20 \\
\text { min. }\end{array}$ & $\begin{array}{c}28 \\
\text { min. }\end{array}$ & $\begin{array}{c}24 \\
\text { min. }\end{array}$ & $\begin{array}{c}25 \\
\text { min. }\end{array}$ & $\begin{array}{c}18 \\
\text { min. }\end{array}$ & $\begin{array}{c}27 \\
\text { min. }\end{array}$ & $\begin{array}{c}21 \\
\text { min. }\end{array}$ & $\begin{array}{c}22 \\
\text { min. }\end{array}$ \\
\hline $\begin{array}{l}\text { Melt flow rate, } \mathrm{g} / 10 \mathrm{~min} \\
\mathrm{~T}=170^{\circ} \mathrm{C}, \mathrm{P}=16,6 \mathrm{kgf}\end{array}$ & 4,3 & 5,1 & 5,4 & 4,4 & 4,6 & 4,0 & 4,5 & 4,8 & 5,1 \\
\hline
\end{tabular}

when moving from oxypropylated to ethoxylated compounds. This is apparently due to the presence of a side methyl group in the alcohol part of the oxypropylated compounds.

At the next stage of producing multi-layer polyvinyl chloride linoleum, the films were connected in a duplication unit which consists of heated drums, rubberized pressure rollers and a cooler conveyor.

Results of testing are shown in Table 7.

As it can be seen from the Table 7, the plasticization of PVC films with oxyalkylated alcohols phthalates positively influence on the performance characteristics - abrasion, change in linear dimensions and absolute deformation set - of multilayer linoleum.

\section{CONCLUSION}

Thus, the use of developed plasticizers in PVC materials improves their main physical and mechanical, technological and operational characteristics:

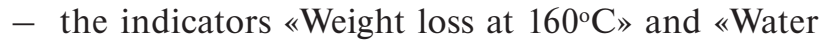
absorption plastics» are improved in soft cable compound;

- the indicators «Breaking strength», «Tensile strain», «Shatter temperature» and «Thermostability» are improved in PVC adhesive tape;

- the indicators «Abrasion», "Change in linear dimensions» and «Absolute deformation set» are at the level of industrial plasticizer DOP in multilayer linoleum.

\section{Table 7}

Results of multilayer linoleum testing

\begin{tabular}{|c|c|c|c|c|}
\hline \multirow{2}{*}{$\begin{array}{c}\text { Plasticizers used in the } \\
\text { preparation of polymer } \\
\text { films }\end{array}$} & $\begin{array}{c}|c| \\
\text { Change in linear } \\
\text { dimensions, } \\
\text { \% no more than }\end{array}$ & $\begin{array}{c}\text { Surface resistivity, } \\
\text { Ohm, no more than }\end{array}$ & $\begin{array}{c}\text { Absolute deformation } \\
\text { set, mm, } \\
\text { no more than }\end{array}$ & $\begin{array}{c}\text { Abrasion, mcm, } \\
\text { no more than }\end{array}$ \\
\hline $\begin{array}{c}\text { Norms according } \\
\text { to 7251-77 }\end{array}$ & 0,80 & $5,0 \cdot 10^{15}$ & 0,45 & 90 \\
\hline Control sample & 0,71 & $17,4 \cdot 10^{12}$ & 0,42 & 86 \\
\hline I & 0,57 & $3,4 \cdot 10^{12}$ & 0,35 & 74 \\
\hline II & 0,47 & $4,2 \cdot 10^{12}$ & 0,26 & 44 \\
\hline III & 0,52 & $3,9 \cdot 10^{12}$ & 0,34 & 45 \\
\hline IV & 0,42 & $4,1 \cdot 10^{12}$ & 0,32 & 51 \\
\hline V & 0,65 & $3,2 \cdot 10^{12}$ & 0,39 & 82 \\
\hline VI & 0,55 & $4,1 \cdot 10^{12}$ & 0,30 & 52 \\
\hline VII & 0,45 & $3,6 \cdot 10^{12}$ & 0,29 & 47 \\
\hline VIII & 0,50 & $3,8 \cdot 10^{12}$ & 0,27 & 54 \\
\hline
\end{tabular}




\section{ВВЕДЕНИЕ}

$\Pi$ оливинилхлорид (ПВХ) является одним из самых востребованных крупнотоннажных полимеров, производимых как в России, так и за рубежом. Причиной этого является исключительная способность практически любыми способами перерабатываться в значительный ассортимент материалов и изделий различного назначения. Как известно, в последние годы наметилась тенденция к возрастанию требований к эксплуатационным и технологическим свойствам получаемых на основе поливинилхлорида материалов и изделий. Поэтому добавки также должны соответствовать предъявляемым требованиям.

В мире ежегодно производится более 12 млн. тонн полимерных добавок. Главная роль химикатов-добавок - облегчение переработки полимерных смесей и придание готовым изделиям необходимых свойств. Применение добавок позволяет получать самые разнообразные продукты - от очень мягких, гелеобразных, до упругих, жестких материалов [1...4].

Среди добавок наибольшую долю занимают пластификаторы (более 50\%). На первом месте по потреблению пластификаторов находятся эфиры фталевой кислоты [4].

Основным представителем фталатных пластификаторов является диоктилфталат (ДОФ), который считается международным стандартным пластификатором ПВХ, удовлетворяющим требованиям переработки. Он имеет оптимальное сочетание свойств, сравнительно дешевый, обеспечивает необходимый комплекс эксплуатационных свойств, но относится к веществам II класса опасности. Тем не менее, ДОФ все еще остается наиболее распространенным сложноэфирным пластификатором ПВХ [1...6].

Поэтому разработка новых эффективных и экологичных пластификаторов является актуальной и имеет важное практическое значение.

\section{ЭКСПЕРИМЕНТАЛЬНАЯ ЧАСТЬ}

Нами проводятся исследования по разработке новых пластификаторов [7...17]. В данной работе приводятся методы синтеза, некоторые физико-химические свойства и результаты испытаний фталатов оксиалкилированных спиртов в некоторых ПВХкомпозициях строительного назначения, а именно в рецептурах кабельного ПВХ-пластиката марки О-40 рец. ОМ-40 (черный), ленты ПВХ липкой и многослойного линолеума.

Целевые сложные эфиры с 3-м классом опасности получали в два этапа. В первую очередь синтезировали оксиалкилированные спирты. Затем этерификацией их с фталевым ангидридом получали конечные продукты.

\section{Методика оксиалкилирования спиртов}

В четырехгорлую колбу, снабженную мешалкой, термометром, обратным холодильником и устройством для ввода оксида этилена (пропилена) загружают расчетное количество спирта и катализатора едкого натра. Реактор нагревают на масляной бане и продувают азотом для удаления воздуха. Затем постепенно (при работающей мешалке) вводят оксид этилена (пропилена). Скорость подачи окиси этилена (пропилена) регулируют таким образом, чтобы не вступившая в реакцию окись конденсировалась в обратном холодильнике и стекала обратно в реактор «без захлебывания». После подачи оксида этилена (пропилена) реакционную смесь дополнительно нагревают и затем охлаждают до комнатной температуры.

Катализатор нейтрализуют расчетным количеством серной кислоты и полученную массу фильтруют.

\section{Методика этерификации фталевого ангидрида}

В трехгорлую колбу, снабженную холодильником с ловушкой Дина-Старка, термометром и механической мешалкой, помещают фталевый ангидрид, оксиалкилированный спирт и катализатор n-толуолсульфокислоту (ПТСК) или тетрабутоксититан. Реакцию ведут до тех пор, пока в ловушке не образуется расчетное количество воды. По окончании реакции катализатор гидролизуют водой и этерификат отфильтровывают. При использовании ПТСК для облегчения удаления образующейся воды через реакционную смесь барботируют инертный газ - диоксид углерода или азот.

Общая схема получения фталатов оксиалкилированных спиртов имеет следующий вид:

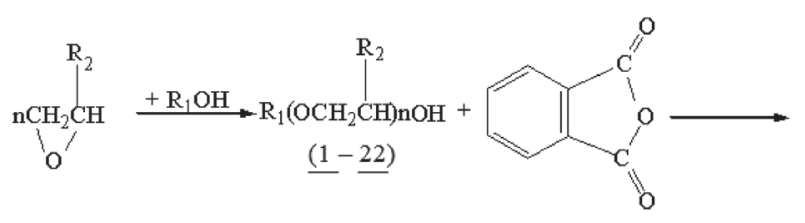

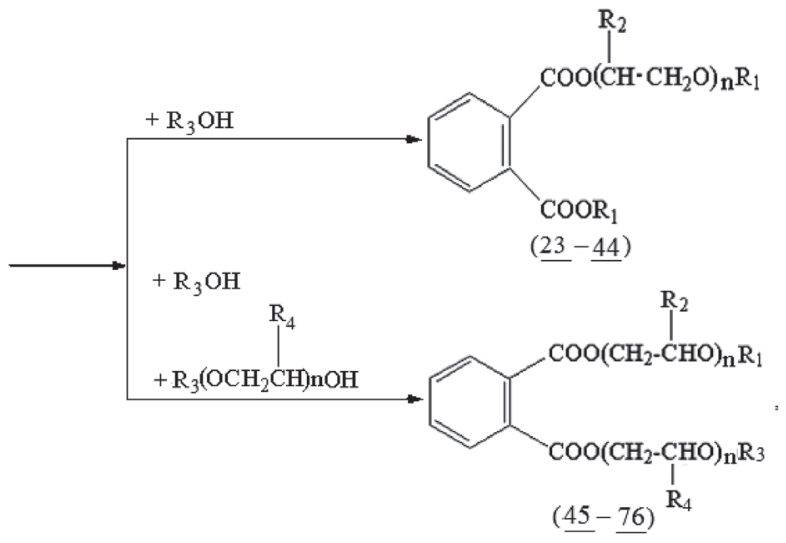


где $\mathrm{R}_{1}=\mathrm{C}_{4} \mathrm{H}_{9} ; \mathrm{C}_{8} \mathrm{H}_{17} ; \mathrm{C}_{6} \mathrm{H}_{5} ; \mathrm{C}_{6} \mathrm{H}_{5} \mathrm{CH}_{2} ; \mathrm{R}_{2}=\mathrm{H} ; \mathrm{CH}_{3} ;$ $\mathrm{R}_{3}=\mathrm{C}_{4} \mathrm{H}_{9} ; \mathrm{C}_{8} \mathrm{H}_{17} ; \mathrm{C}_{6} \mathrm{H}_{5} ; \mathrm{C}_{6} \mathrm{H}_{5} \mathrm{CH}_{2} ; \mathrm{R}_{4}=\mathrm{H} ; \mathrm{CH}_{3}$.

Условия, позволяющие получить пластификаторы с выходом более $80 \%$, приведены в табл. 1 .

Физико-химические показатели синтезированных соединений приведены в табл.2, 3.

Из табл. 2 видно, что с повышением степени оксиалкилирования плотность и показатель преломления растут.

Из полученных результатов видно, что с увеличением степени оксиалкилирования показатель преломления эфиров снижается, а плотность растет. Физико-химические показатели пластификаторов анализировали согласно ГОСТ 8728-88.

\section{ОБСУЖДЕНИЕ РЕЗУЛЬТАТОВ}

Для определения эффективности разработанных пластификаторов было исследовано изменение твердости по Шору А от концентрации пластификатора (пластификатор:ПВХ - 1:100). На основании расчета количественного фактора замещения (Ф3), определяющего требуемое количество фталатов оксиалкилированных спиртов по сравнению с ДОФ и обеспечивающего необходимую твердость гибкого ПВХ при комнатных условиях, было установлено, что соединения $24,29,31,35,39,44,47,50,53,57,61,62$, 67 очень схожи с ДОФ по пластифицирующей эффективности. Для этих пластификаторов характерна

\section{Таблииа 1}

Оптимальные условия для получения химикатов-добавок

\begin{tabular}{|c|c|c|c|c|}
\hline Синтезированные соединения & $\begin{array}{r}\text { Мольное соо } \\
\text { ние реаге }\end{array}$ & $\begin{array}{l}\text { оше- } \\
\text { B }\end{array}$ & $\begin{array}{l}\text { Темпера- } \\
\text { тура, }^{\circ} \mathrm{C}\end{array}$ & Примечание \\
\hline $\begin{array}{l}\left.\right|_{\mathrm{R}_{1}\left(\mathrm{OCH}_{2} \mathrm{CH}\right) \mathrm{nOH} ;} ^{\mathrm{R}_{2}} \\
\text { где } \mathrm{R}_{1}=\mathrm{C}_{4} \mathrm{H}_{9} ; \mathrm{R}_{2}=\mathrm{H}(1-4), \mathrm{CH}_{3}(5-8) ; \\
\mathrm{R}_{1}=\mathrm{C}_{8} \mathrm{H}_{17} ; \mathrm{R}_{2}=\mathrm{H}(9-12), \mathrm{CH}_{3}(13-16) ; \\
\mathrm{R}_{1}=\mathrm{C}_{6} \mathrm{H}_{5} ; \mathrm{R}_{2}=\mathrm{H}(17), \mathrm{CH}_{3}(18) ; \\
\mathrm{R}_{1}=\mathrm{C}_{6} \mathrm{H}_{5} \mathrm{CH}_{2} ; \mathrm{R}_{2}=\mathrm{CH}_{3}(19-22)\end{array}$ & $\begin{array}{l}\text { Спирт: оксид } \\
\text { этилена } \\
\text { (пропилена) }\end{array}$ & $1: 1-3$ & $110-180$ & $\begin{array}{l}\text { количество } \\
\text { катализатора 0,5-3\% } \\
\text { (масс. от загрузки) }\end{array}$ \\
\hline $\begin{array}{l}\text { г्Oe } \mathrm{R}_{1}=\mathrm{C}_{4} \mathrm{H}_{9} ; \mathrm{R}_{3}=\mathrm{C}_{4} \mathrm{H}_{9} ; \mathrm{R} 2=\mathrm{H}(23-26), \mathrm{CH}_{3}(27-30) ; \\
\mathrm{R}_{1}=\mathrm{C}_{8} \mathrm{H}_{17} ; \mathrm{R}_{3}=\mathrm{C}_{8} \mathrm{H}_{17} ; \mathrm{R}_{2}=\mathrm{H}(31-34), \mathrm{CH}_{3}(35-38) ; \\
\mathrm{R}_{1}=\mathrm{C}_{6} \mathrm{H}_{5} \mathrm{CH}_{2} ; \mathrm{R}_{3}=\mathrm{C}_{6} \mathrm{H}_{5} \mathrm{CH}_{2} ; \mathrm{R}_{2}=\mathrm{CH}_{3}(39-42) ; \\
\mathrm{R}_{1}=\mathrm{C}_{8} \mathrm{H}_{17} ; \mathrm{R}_{3}=\mathrm{C}_{6} \mathrm{H}_{5} ; \mathrm{R}_{2}=\mathrm{H}(43), \mathrm{CH}_{3}(44) .\end{array}$ & $\begin{array}{l}\text { Фталевый ан- } \\
\text { гидрид: окси- } \\
\text { алкилирован- } \\
\text { ный спирт }\end{array}$ & $1: 1,5$ & $110-140$ & $\begin{array}{l}\text { количество } \\
\text { катализатора } 0,1-2 \% \\
\text { (масс. от загрузки) + } \\
\text { активированный } \\
\text { уголь в количестве } \\
1 \% \text { (масс. от массы } \\
\text { загруженных } \\
\text { компонентов) }\end{array}$ \\
\hline $\begin{array}{l}\mathrm{COO}\left(\mathrm{CH}_{2}-\mathrm{CHO}\right)_{n} \mathrm{R}_{1} \\
\text { где } \mathrm{R}_{1}=\mathrm{C}_{4} \mathrm{H}_{9} ; \mathrm{R}_{3}=\mathrm{C}_{4} \mathrm{H}_{9} ; \mathrm{R}_{2}=\mathrm{H}(45-48), \mathrm{R}_{4}=\mathrm{CH}_{3}(49-52) ; \\
\mathrm{R}_{1}=\mathrm{C}_{8} \mathrm{H}_{17} ; \mathrm{R}_{3}=\mathrm{C}_{8} \mathrm{H}_{17} ; \mathrm{R}_{2}=\mathrm{H}(53-56), \mathrm{R}_{4}=\mathrm{CH}_{3}(57-60) ; \\
\mathrm{R}_{1}=\mathrm{C}_{6} \mathrm{H}_{5} ; \mathrm{R}_{3}=\mathrm{C}_{4} \mathrm{H}_{9} ; \mathrm{R}_{2}=\mathrm{H} ; \mathrm{R}_{4}=\mathrm{H}(61-64) ; \\
\mathrm{R}_{1}=\mathrm{C}_{6} \mathrm{H}_{5} ; \mathrm{R}_{3}=\mathrm{C}_{4} \mathrm{H}_{9} ; \mathrm{R}_{2}=\mathrm{CH}_{3} ; \mathrm{R}_{4}=\mathrm{CH}_{3}(65-68) ; \\
\mathrm{R}_{1}=\mathrm{C}_{6} \mathrm{H}_{5} ; \mathrm{R}_{3}=\mathrm{C}_{4} \mathrm{H}_{9} ; \mathrm{R}_{2}=\mathrm{H}_{2} ; \mathrm{R}_{4}=\mathrm{CH}_{3}(69-72) ; \\
\mathrm{R}_{1}=\mathrm{C}_{6} \mathrm{H}_{5} ; \mathrm{R}_{3}=\mathrm{C}_{4} \mathrm{H}_{9} ; \mathrm{R}_{2}=\mathrm{CH}_{3} ; \mathrm{R}_{4}=\mathrm{H}(73-76)\end{array}$ & $\begin{array}{l}\text { Фталевый ан- } \\
\text { гидрид: окси- } \\
\text { алкилирован- } \\
\text { ный спирт }\end{array}$ & $1: 2,5$ & $120-180$ & $\begin{array}{l}\text { количество } \\
\text { катализатора } 0,1-2 \% \\
\text { (масс. от загрузки) + } \\
\text { активированный } \\
\text { уголь в количестве } \\
1 \% \text { (масс. от массы } \\
\text { загруженных } \\
\text { компонентов) }\end{array}$ \\
\hline
\end{tabular}


Таблица 2

Физико-химические свойства оксиалкилированных спиртов

\begin{tabular}{|c|c|c|c|c|c|}
\hline $\begin{array}{c}\text { № } \\
\text { соединения }\end{array}$ & $\mathbf{n}$ & $\mathrm{d}^{20}{ }_{4}$ & $\mathbf{n}^{20}$ & Э. ч., мг КОН/г & М. м. найдено \\
\hline \multicolumn{6}{|c|}{ Оксиэтилированные бутанолы } \\
\hline 1 & 1,5 & 0,9745 & 1,4285 & 790 & 142 \\
\hline 2 & 2,0 & 0,9842 & 1,4333 & 681 & 165 \\
\hline 3 & 2,2 & 0,9875 & 1,4351 & 644 & 173 \\
\hline 4 & 2,4 & 0,9895 & 1,4369 & 615 & 182 \\
\hline \multicolumn{6}{|c|}{ Оксипропилированные бутанолы } \\
\hline 5 & 1,5 & 0,9130 & 1,4274 & 693 & 162 \\
\hline 6 & 2,0 & 0,9224 & 1,4289 & 586 & 192 \\
\hline 7 & 2,2 & 0,9253 & 1,4296 & 552 & 203 \\
\hline 8 & 2,4 & 0,9287 & 1,4303 & 522 & 215 \\
\hline \multicolumn{6}{|c|}{ Оксиэтилированные 2-этилгексанолы } \\
\hline 9 & 1,5 & 0,9141 & 1,4325 & 568 & 197 \\
\hline 10 & 2,0 & 0,9240 & 1,4490 & 510 & 220 \\
\hline 11 & 2,4 & 0,9309 & 1,4580 & 471 & 238 \\
\hline 12 & 3,0 & 0,9382 & 1,4696 & 422 & 265 \\
\hline \multicolumn{6}{|c|}{ Оксипропилированные 2-этилгексаноль } \\
\hline 13 & 1,3 & 0,8757 & 1,4329 & 538 & 208 \\
\hline 14 & 1,9 & 0,8787 & 1,4342 & 461 & 243 \\
\hline 15 & 2,3 & 0,8841 & 1,4358 & 423 & 265 \\
\hline 16 & 2,7 & 0,8911 & 1,4379 & 386 & 290 \\
\hline \multicolumn{6}{|c|}{ Оксиэтилированный фенол } \\
\hline 17 & 1,0 & 1,1007 & 1,5314 & 789 & 142 \\
\hline \multicolumn{6}{|c|}{ Оксипропилированный фенол } \\
\hline 18 & 2,1 & 1,0773 & 1,5338 & 514 & 218 \\
\hline \multicolumn{6}{|c|}{ Оксипропилированные фенилкарбинолы } \\
\hline 19 & 1,1 & 1,0114 & 1,5216 & 640 & 175 \\
\hline 20 & 1,7 & 1,0136 & 1,5259 & 533 & 210 \\
\hline 21 & 2,4 & 1,0162 & 1,5298 & 448 & 250 \\
\hline 22 & 2,7 & 1,0176 & 1,5318 & 416 & 269 \\
\hline
\end{tabular}

хорошая растворяющая способность ПВХ и низкая склонность к миграции из пластифицированной пленки, ведь, как известно, миграция пластификатора из материала играет большое значение в сохранении свойств ПВХ-материалов при эксплуатации в течение длительного времени [1]. Исследование пластифицирующих свойств показало, что полученные ПВХ-пленки не имеют видимых признаков выпотевания пластификатора и обладают хорошими эластичными свойствами.

Выбранные образцы были испытаны в некоторых ПВХ-композициях строительного назначения.
Испытание пластификаторов в рецептуре кабельного пластиката марки O-40рец. ОМ-40(ч)

Полученные образцы кабельных пластикатов марки О-40 рец. ОМ-40 (черный) анализировали по ГОСТ 5960-72 с изм. 1-9 «Пластикат поливинилхлоридный для изоляции и защитных оболочек проводов и кабелей». Результаты испытаний приведены в табл. 4.

Приведенные в табл. данные показывают, что по основным показателям - прочности при разрыве, относительном удлинении при разрыве, температу- 
Nanotechnologies in Construction: A Scientific Internet-Journal

Таблица 3

Физико-химические свойства фталатов оксиалкилированных спиртов

\begin{tabular}{|c|c|c|c|c|c|c|}
\hline № соединения & $\mathbf{n}$ & $\mathrm{n}^{20}{ }_{\mathrm{D}}$ & $\mathrm{d}^{20}{ }_{4}$ & $\begin{array}{c}\text { К. ч., мг } \\
\text { КОН/г }\end{array}$ & $\begin{array}{l}\text { Э. ч., мг } \\
\text { КОН/Г }\end{array}$ & М. м. найдено \\
\hline 1 & 2 & 3 & 4 & 5 & 6 & 7 \\
\hline \multicolumn{7}{|c|}{ Бутилбутоксиэтилфталаты } \\
\hline 23 & 1,5 & 1,4889 & 1,0559 & 0,10 & 321 & 349 \\
\hline 24 & 2,0 & 1,4883 & 1,0581 & 0,10 & 302 & 371 \\
\hline 25 & 2,2 & 1,4879 & 1,0601 & 0,10 & 295 & 380 \\
\hline 26 & 2,4 & 1,4874 & 1,0615 & 0,10 & 288 & 389 \\
\hline \multicolumn{7}{|c|}{ Бутилбутоксипропилфталаты } \\
\hline 27 & 1,5 & 1,4814 & 1,0237 & 0,05 & 303 & 370 \\
\hline 28 & 2,0 & 1,4796 & 1,0298 & 0,08 & 281 & 399 \\
\hline 29 & 2,2 & 1,4781 & 1,0307 & 0,08 & 272 & 412 \\
\hline 30 & 2,4 & 1,4775 & 1,0324 & 0,10 & 265 & 422 \\
\hline \multicolumn{7}{|c|}{ Октилоктоксиэтилфталаты } \\
\hline 31 & 1,5 & 1,4812 & 0,9875 & 0,10 & 242 & 463 \\
\hline 32 & 2,0 & 1,4790 & 0,9930 & 0,10 & 231 & 485 \\
\hline 33 & 2,4 & 1,4768 & 0,9986 & 0,10 & 222 & 505 \\
\hline 34 & 3,0 & 1,4748 & 1,0097 & 0,10 & 213 & 526 \\
\hline \multicolumn{7}{|c|}{ Октилоктоксипроптилфталаты } \\
\hline 35 & 1,3 & 1,4775 & 0,9681 & 0,20 & 237 & 473 \\
\hline 36 & 1,9 & 1,4745 & 0,9738 & 0,20 & 220 & 509 \\
\hline 37 & 2,3 & 1,4733 & 0,9776 & 0,20 & 210 & 533 \\
\hline 38 & 2,7 & 1,4719 & 0,9813 & 0,20 & 201 & 557 \\
\hline \multicolumn{7}{|c|}{ Бензилбензоксипропилфталаты } \\
\hline 39 & 1,1 & 1,5189 & 1,1075 & 0,20 & 271 & 413 \\
\hline 40 & 1,7 & 1,5178 & 1,1098 & 0,15 & 250 & 448 \\
\hline 41 & 2,4 & 1,5168 & 1,1122 & 0,20 & 229 & 489 \\
\hline 42 & 2,7 & 1,5163 & 1,1136 & 1,15 & 222 & 505 \\
\hline \multicolumn{7}{|c|}{ Октилфеноксиэтилфталаты } \\
\hline 43 & 1,0 & 1,4863 & 1,0214 & 0,10 & 313 & 358 \\
\hline \multicolumn{7}{|c|}{ Октилфеноксипропилфталаты } \\
\hline 44 & 2,1 & 1,4756 & 1,0098 & 0,10 & 232 & 481 \\
\hline \multicolumn{7}{|c|}{ Дибутоксиэтилфталаты } \\
\hline 45 & 1,5 & 1,0648 & 1,4855 & 0,20 & 271 & 413 \\
\hline 46 & 2,0 & 1,0757 & 1,4816 & 0,10 & 243 & 461 \\
\hline 47 & 2,2 & 1,0837 & 1,4755 & 0,10 & 236 & 475 \\
\hline 48 & 2,4 & 1,0863 & 1,4742 & 0,20 & 226 & 496 \\
\hline \multicolumn{7}{|c|}{ Дибутоксипропилфталаты } \\
\hline 49 & 1,5 & 1,0286 & 1,4779 & 0,30 & 246 & 456 \\
\hline 50 & 2,0 & 1,0296 & 1,4751 & 0,40 & 217 & 515 \\
\hline 51 & 2,2 & 1,0299 & 1,4745 & 0,30 & 207 & 541 \\
\hline 52 & 2,4 & 1,0304 & 1,4739 & 0,30 & 200 & 561 \\
\hline
\end{tabular}


Nanotechnologies in Construction: A Scientific Internet-Journal

Окончание табл. 3

\begin{tabular}{|c|c|c|c|c|c|c|}
\hline 1 & 2 & 3 & 4 & 5 & 6 & 7 \\
\hline \multicolumn{7}{|c|}{ Диоктоксиэтилфталаты } \\
\hline 53 & 1,5 & 0,9887 & 1,4797 & 0,30 & 211 & 531 \\
\hline 54 & 2,0 & 0,9982 & 1,4783 & 0,30 & 195 & 574 \\
\hline 55 & 2,4 & 1,0047 & 1,4772 & 0,38 & 183 & 612 \\
\hline 56 & 3,0 & 1,0132 & 1,4754 & 0,30 & 168 & 667 \\
\hline \multicolumn{7}{|c|}{ Диоктоксипропилфталаты } \\
\hline 57 & 1,3 & 0,9642 & 1,4619 & 0,30 & 203 & 552 \\
\hline 58 & 1,9 & 0,9978 & 1,4607 & 0,40 & 180 & 622 \\
\hline 59 & 2,3 & 1,0253 & 1,4599 & 0,30 & 166 & 675 \\
\hline 60 & 2,7 & 1,0429 & 1,4594 & 0,50 & 155 & 722 \\
\hline \multicolumn{7}{|c|}{ Бутоксиэтилфеноксиэтилфталаты } \\
\hline 61 & 1,5 & 1,5190 & 1,1054 & 0,20 & 271 & 415 \\
\hline 62 & 2,0 & 1,5183 & 1,1081 & 0,20 & 257 & 436 \\
\hline 63 & 2,2 & 1,5180 & 1,1110 & 0,20 & 252 & 444 \\
\hline 64 & 2,4 & 1,5176 & 1,1119 & 0,20 & 247 & 454 \\
\hline \multicolumn{7}{|c|}{ Бутоксипропилфеноксипропилфталаты } \\
\hline 65 & 1,5 & 1,5184 & 1,1034 & 0,20 & 201 & 558 \\
\hline 66 & 2,0 & 1,5178 & 1,1062 & 0,20 & 211 & 514 \\
\hline 67 & 2,2 & 1,5175 & 1,1078 & 0,20 & 214 & 524 \\
\hline 68 & 2,4 & 1,5172 & 1,1091 & 0,20 & 218 & 531 \\
\hline \multicolumn{7}{|c|}{ Бутоксиэтилфеноксипропилфталаты } \\
\hline 69 & 1,5 & 1,5184 & 1,1034 & 0,20 & 201 & 558 \\
\hline 70 & 2,0 & 1,5178 & 1,1062 & 0,20 & 211 & 514 \\
\hline 71 & 2,2 & 1,5175 & 1,1078 & 0,20 & 214 & 524 \\
\hline 72 & 2,4 & 1,5172 & 1,1091 & 0,20 & 218 & 531 \\
\hline \multicolumn{7}{|c|}{ Бутоксипропилфеноксиэтилфталаты } \\
\hline 73 & 1,5 & 1,5187 & 1,1014 & 0,20 & 257 & 435 \\
\hline 74 & 2,0 & 1,5183 & 1,1042 & 0,20 & 241 & 464 \\
\hline 75 & 2,2 & 1,5178 & 1,1060 & 0,20 & 235 & 476 \\
\hline 76 & 2,4 & 1,5174 & 1,1074 & 0,20 & 230 & 486 \\
\hline
\end{tabular}

ре хрупкости - полученные кабельные пластикаты не уступают промышленным образцам, а такие показатели как «Потери в массе при $160^{\circ} \mathrm{C}$ » и «одопоглощение» значительно ниже при использовании бутилбутоксипропилфталата, дибутоксиэтилфталата и дибутоксипропилфталата.

Испытание пластификаторов в рецептуре ленты ПВХлипкой

Полученные образцы ленты ПВХ липкой анализировали согласно ТУ 2245-001-00203312-2003 (Лента поливинилхлоридная липкая). Результаты испытаний приведены в табл. 5.

Согласно табличным данным, лента ПВХ липкая соответствуют техническим требованиям. Отмечено, что при использовании полученных нами сложноэфирных соединений улучшаются показатели, а именно: «Прочность при разрыве», «Относительное удлинение», «Температура хрупкости» и «Термостабильность». Практически во всех случаях указанные образцы обеспечивают технологические и эксплуатационные показатели выше уровня серийного пластификатора ДОФ. 


\section{Таблица 4}

Результаты испытаний пластификаторов в рецептуре кабельного пластиката марки 0-40 рец. ОМ-40 (ч)

\begin{tabular}{|c|c|c|c|c|c|c|}
\hline \multirow{5}{*}{$\begin{array}{l}\text { Наименование } \\
\text { показателей }\end{array}$} & \multicolumn{6}{|c|}{ Пластификатор } \\
\hline & \multirow{4}{*}{\begin{tabular}{|c|} 
Норма \\
по ГОСТ 5960-72 \\
с изм. 1-9 \\
(1 сорт)
\end{tabular}} & \multirow{4}{*}{$\begin{array}{c}\text { Кон- } \\
\text { трольный } \\
\text { образец }\end{array}$} & \multicolumn{4}{|c|}{ № соединения } \\
\hline & & & 47 & 50 & 24 & 29 \\
\hline & & & \multicolumn{4}{|c|}{ № образца } \\
\hline & & & I & II & III & IV \\
\hline $\begin{array}{l}\text { Удельное объемное электр. } \\
\text { сопротивление при } 20^{\circ} \mathrm{C}, \mathrm{OM} \cdot \mathrm{cm}\end{array}$ & Не менее $1 \cdot 10^{10}$ & $9,0 \bullet 10^{12}$ & $6,3 \cdot 10^{12}$ & $4,5 \cdot 10^{12}$ & $7,5 \cdot 10^{12}$ & $6,0 \cdot 10^{12}$ \\
\hline Прочность при разрыве, кгс/см² & Не менее 110 & 147 & 140 & 142 & 144 & 140 \\
\hline $\begin{array}{l}\text { Относительное удлинение } \\
\text { при разрыве, \% }\end{array}$ & Не менее 280 & 385 & 328 & 345 & 336 & 276 \\
\hline Температура хрупкости, ${ }^{\circ} \mathrm{C}$ & Не выше -40 & \multicolumn{5}{|c|}{ выдерживают } \\
\hline $\begin{array}{l}\text { Потери в массе при } 160^{\circ} \mathrm{C}, \\
\text { в течение } 6 \text { ч., \% }\end{array}$ & Не более 3,0 & 2,2 & 2,0 & 1,7 & 1,8 & 1,6 \\
\hline 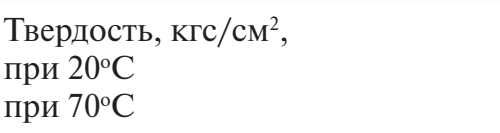 & $\begin{array}{l}\text { Не менее } \\
9-20 \\
6-12\end{array}$ & $\begin{array}{c}12,5 \\
7,3\end{array}$ & $\begin{array}{l}11,3 \\
7,2\end{array}$ & $\begin{array}{c}11,8 \\
7,1\end{array}$ & $\begin{array}{l}12,1 \\
7,3\end{array}$ & $\begin{array}{l}11,9 \\
7,4\end{array}$ \\
\hline Водопоглощение, \% & Не более 0,45 & 0,080 & 0,040 & 0,052 & 0,350 & 0,053 \\
\hline Температура размягчения, ${ }^{\circ} \mathrm{C}$ & $170 \pm 10$ & 171 & 171 & 172 & 169 & 171 \\
\hline 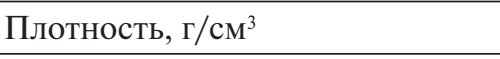 & Не более 1,4 & 1,38 & 1,39 & 1,38 & 1,39 & 1,38 \\
\hline \multicolumn{7}{|c|}{ Технологические свойства } \\
\hline $\begin{array}{l}\text { Термостабильность при } 180^{\circ} \mathrm{C} \text {, } \\
\text { мин. }\end{array}$ & ГОСТ 14041-91 & 2 ч. 15 мин. & 2 ч. 16 мин. & 2 ч. 24 мин. & 2 ч. 35 мин. & 2 ч. 12 мин. \\
\hline $\begin{array}{l}\text { ПТР, г/10 мин при } 190^{\circ} \mathrm{C}, \\
\mathrm{P}=10 \mathrm{Kгc} / \mathrm{cm}^{2}\end{array}$ & ГОСТ 11645-73 & 103,3 & 106,3 & 102,0 & 98,7 & 102,4 \\
\hline
\end{tabular}

Таблица 5

Результаты испытаний ленты ПВХ липкой

\begin{tabular}{|c|c|c|c|c|c|c|c|c|c|c|c|}
\hline \multirow{5}{*}{$\begin{array}{c}\text { Наименование } \\
\text { показателя }\end{array}$} & \multicolumn{11}{|c|}{ Пластификатор } \\
\hline & \multirow{4}{*}{$\begin{array}{l}\text { Нормы ТУ } \\
2245-001- \\
00203312- \\
2003\end{array}$} & \multirow{4}{*}{$\begin{array}{c}\text { Кон- } \\
\text { троль- } \\
\text { ный } \\
\text { обра- } \\
\text { зец }\end{array}$} & \multicolumn{9}{|c|}{ № соединения } \\
\hline & & & 53 & 57 & 31 & 35 & 62 & 61 & 67 & 39 & 44 \\
\hline & & & \multicolumn{9}{|c|}{ № образца } \\
\hline & & & $\mathbf{V}$ & VI & VII & VIII & IX & $\mathbf{X}$ & XI & XII & XIII \\
\hline $\begin{array}{l}\text { Прочность при } \\
\text { разрыве, кгс } / \mathrm{cm}^{2}\end{array}$ & Не менее 50 & 73 & 65 & 71 & 69 & 73 & 65 & 71 & 69 & 70 & 72 \\
\hline $\begin{array}{l}\text { Относительное } \\
\text { удлинение, \% }\end{array}$ & Не менее 280 & 277 & 258 & 262 & 281 & 276 & 258 & 262 & 281 & 276 & 275 \\
\hline $\begin{array}{l}\text { Температура } \\
\text { хрупкости, }{ }^{\circ} \mathrm{C}\end{array}$ & Не выше -30 & \multicolumn{10}{|c|}{ выдерживают } \\
\hline \multicolumn{12}{|c|}{ Технологические свойства } \\
\hline $\begin{array}{l}\text { Термостабильность } \\
\text { при } 170^{\circ} \mathrm{C}, \text { мин. }\end{array}$ & $\begin{array}{c}\text { ГОСТ } \\
14041-91\end{array}$ & $\begin{array}{l}2 \text { ч. } 07 \\
\text { мин. }\end{array}$ & $\begin{array}{c}2 \text { ч. } 05 \\
\text { мин. }\end{array}$ & $\begin{array}{l}2 \text { ч. } 15 \\
\text { мин. }\end{array}$ & $\begin{array}{c}2 \text { ч. } 59 \\
\text { мин. }\end{array}$ & \begin{tabular}{|c|}
2 ч. 06 \\
мин.
\end{tabular} & $\begin{array}{l}2 \text { ч. } 11 \\
\text { мин. }\end{array}$ & $\begin{array}{c}2 \text { ч. } 08 \\
\text { мин. }\end{array}$ & $\begin{array}{c}2 \text { ч. } 27 \\
\text { мин. }\end{array}$ & $\begin{array}{c}2 \text { ч. } 29 \\
\text { мин. }\end{array}$ & $\begin{array}{l}2 \text { ч. } 06 \\
\text { мин. }\end{array}$ \\
\hline $\begin{array}{l}\text { ПТР, при } \mathrm{T}=180^{\circ} \mathrm{C}, \\
\mathrm{H}=16,6 \text { кгс, г } / 10 \text { мин. }\end{array}$ & $\begin{array}{c}\text { ГОСТ } \\
11645-73\end{array}$ & 10,5 & 14,8 & 12,5 & 14,2 & 12,8 & 14,8 & 12,5 & 14,2 & 13,8 & 14,1 \\
\hline
\end{tabular}




\section{DEVELOPMENT OF NEW POLYMER MATERIALS • РАЗРАБОТКА НОВЫХ ПОЛИМЕРНЫХ МАTЕРИАЛОВ}

Испытание пластификаторов в многослойном линолеуме

Для изготовления многослойного безосновного линолеума предварительно были получены поливинилхлоридные пленки: верхний прозрачный, средний и нижний слой, которые анализировали согласно СТП 00203312-100-2006. Результаты испытаний приведены в табл. 6.

Из данных табл. 6 видно, что замена диоктилфталата на фталаты оксиалкилированных спиртов позволяет получить ПВХ-пленки с высокой тер-

\section{Таблица 6}

Результаты испытаний пластификаторов в ПВХ-рецептурах верхнего, среднего, нижнего слоев линолеума

\begin{tabular}{|c|c|c|c|c|c|c|c|c|c|}
\hline \multirow{5}{*}{$\begin{array}{l}\text { Наименование } \\
\text { показателя }\end{array}$} & \multicolumn{9}{|c|}{ Пластификатор } \\
\hline & \multirow{4}{*}{$\begin{array}{c}\text { Нормы } \\
\text { СТП 00203312-100- } \\
2006\end{array}$} & \multicolumn{8}{|c|}{ № соединения } \\
\hline & & 47 & 50 & 24 & 29 & 53 & 57 & 31 & 35 \\
\hline & & \multicolumn{8}{|c|}{ № образца } \\
\hline & & I & II & III & VI & $\mathbf{V}$ & VI & VII & VIII \\
\hline \multicolumn{10}{|c|}{$\begin{array}{c}\text { Промышленная рецептура верхнего слоя линолеума } \\
\text { (Пластикат ПВХ пластифицированный прозрачный с тисненой поверхностью и без тиснения) }\end{array}$} \\
\hline 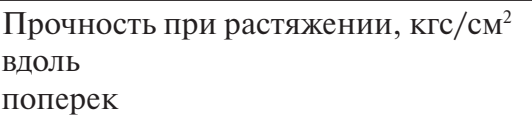 & $\begin{array}{l}\text { Не менее } \\
175 \\
175\end{array}$ & $\begin{array}{l}270 \\
277\end{array}$ & $\begin{array}{l}284 \\
258\end{array}$ & $\begin{array}{l}282 \\
259\end{array}$ & $\begin{array}{l}287 \\
232\end{array}$ & $\begin{array}{l}279 \\
241\end{array}$ & $\begin{array}{l}294 \\
221\end{array}$ & $\begin{array}{l}285 \\
254\end{array}$ & $\begin{array}{l}290 \\
227\end{array}$ \\
\hline $\begin{array}{l}\text { Относительное удлинение при разрыве, \% } \\
\text { вдоль } \\
\text { поперек }\end{array}$ & $\begin{array}{c}\text { Не менее } \\
100 \\
100\end{array}$ & $\begin{array}{l}221 \\
293\end{array}$ & $\begin{array}{l}249 \\
258\end{array}$ & $\begin{array}{l}256 \\
281\end{array}$ & $\begin{array}{l}275 \\
269\end{array}$ & $\begin{array}{l}297 \\
253\end{array}$ & $\begin{array}{l}318 \\
301\end{array}$ & $\begin{array}{l}249 \\
266\end{array}$ & $\begin{array}{l}263 \\
253\end{array}$ \\
\hline Изменение линейных размеров, \% & Не более 3,0 & 1,4 & 1,2 & 1,5 & 1,4 & 2,0 & 1,3 & 1,7 & 1,8 \\
\hline \multicolumn{10}{|c|}{ Технологические показатели } \\
\hline Термостабильность при $180^{\circ} \mathrm{C}$, мин & $\begin{array}{l}\text { Контр. с ДОФ } \\
1 ч .45 \text { мин. }\end{array}$ & $\begin{array}{c}14 . \\
38 \\
\text { мин. }\end{array}$ & $\begin{array}{c}14 . \\
51 \\
\text { мин. }\end{array}$ & $\begin{array}{c}1 ч . \\
41 \\
\text { мин. }\end{array}$ & $\begin{array}{c}1 ч . \\
43 \\
\text { мин. }\end{array}$ & $\begin{array}{c}14 . \\
35 \\
\text { мин. }\end{array}$ & $\begin{array}{c}1 ч . \\
48 \\
\text { мин. }\end{array}$ & $\begin{array}{c}14 . \\
37 \\
\text { мин. }\end{array}$ & $\begin{array}{c}14 . \\
40 \\
\text { мин. }\end{array}$ \\
\hline ПТР, г $/ 10$ мин Т $=170^{\circ} \mathrm{C}, \mathrm{P}=16,6$ кгс & 7,1 & 8,5 & 9,3 & 8,4 & 8,6 & 7,5 & 8,3 & 8,9 & 9,1 \\
\hline \multicolumn{10}{|c|}{$\begin{array}{c}\text { Промышленная рецептура среднего слоя линолеума } \\
\text { (Пластикат ПВХ пластифицированный наполненный натурального цвета) }\end{array}$} \\
\hline $\begin{array}{l}\text { Прочность при растяжении, кгс/см² } \\
\text { вдоль } \\
\text { поперек }\end{array}$ & $\begin{array}{l}\text { Не менее } \\
100 \\
100\end{array}$ & $\begin{array}{l}149 \\
125\end{array}$ & $\begin{array}{l}152 \\
136\end{array}$ & $\begin{array}{l}168 \\
130\end{array}$ & $\begin{array}{l}162 \\
114\end{array}$ & $\begin{array}{l}138 \\
105\end{array}$ & $\begin{array}{l}143 \\
120\end{array}$ & $\begin{array}{l}163 \\
140\end{array}$ & $\begin{array}{l}142 \\
124\end{array}$ \\
\hline $\begin{array}{l}\text { Относительное удлинение при разрыве, } \% \\
\text { вдоль } \\
\text { поперек }\end{array}$ & $\begin{array}{l}\text { Не менее } \\
100 \\
100\end{array}$ & $\begin{array}{l}189 \\
242\end{array}$ & $\begin{array}{l}198 \\
232\end{array}$ & $\begin{array}{l}252 \\
180\end{array}$ & $\begin{array}{l}243 \\
192\end{array}$ & $\begin{array}{l}190 \\
178\end{array}$ & $\begin{array}{l}200 \\
204\end{array}$ & $\begin{array}{l}223 \\
217\end{array}$ & $\begin{array}{l}209 \\
240\end{array}$ \\
\hline Изменение линейных размеров, \% & Не более 3,0 & 1,6 & 1,3 & 1,0 & 1,2 & 1,5 & 1,0 & 1,3 & 1,4 \\
\hline \multicolumn{10}{|c|}{ Технологические показатели } \\
\hline Термостабильность при $180^{\circ} \mathrm{C}$, мин & $\begin{array}{c}\text { Контр. с ДОФ } \\
37 \text { мин. }\end{array}$ & $\begin{array}{c}31 \\
\text { мин. }\end{array}$ & $\begin{array}{c}32 \\
\text { мин. }\end{array}$ & $\begin{array}{c}37 \\
\text { мин. }\end{array}$ & $\begin{array}{c}34 \\
\text { мин. }\end{array}$ & $\begin{array}{c}30 \\
\text { мин. }\end{array}$ & $\begin{array}{c}35 \\
\text { мин. }\end{array}$ & $\begin{array}{c}39 \\
\text { мин. }\end{array}$ & $\begin{array}{c}33 \\
\text { мин. }\end{array}$ \\
\hline ПТР, г $/ 10$ мин Т $=170^{\circ} \mathrm{C}, \mathrm{P}=16,6$ кгс & 8,1 & 9,5 & 9,7 & 10,5 & 9,9 & 8,4 & 8,9 & 10,4 & 9,2 \\
\hline \multicolumn{10}{|c|}{ Промышленная рецептура нижнего слоя линолеума (Пластикат ПВХ пластифицированный наполненный) } \\
\hline $\begin{array}{l}\text { Прочность при растяжении, кгс } / \mathrm{cm}^{2} \\
\text { вдоль } \\
\text { поперек }\end{array}$ & $\begin{array}{l}\text { Не менее } \\
75 \\
75 \\
\end{array}$ & $\begin{array}{l}116 \\
80\end{array}$ & $\begin{array}{c}127 \\
91\end{array}$ & $\begin{array}{l}133 \\
116\end{array}$ & $\begin{array}{l}136 \\
118\end{array}$ & $\begin{array}{l}117 \\
85\end{array}$ & $\begin{array}{l}133 \\
103\end{array}$ & $\begin{array}{c}129 \\
99\end{array}$ & $\begin{array}{l}131 \\
100\end{array}$ \\
\hline $\begin{array}{l}\text { Относительное удлинение при разрыве, \% } \\
\text { вдоль } \\
\text { поперек }\end{array}$ & $\begin{array}{l}\text { Не менее } \\
100 \\
100\end{array}$ & $\begin{array}{l}211 \\
151\end{array}$ & $\begin{array}{l}233 \\
208\end{array}$ & $\begin{array}{l}209 \\
152\end{array}$ & $\begin{array}{l}223 \\
163\end{array}$ & $\begin{array}{l}208 \\
157\end{array}$ & $\begin{array}{l}231 \\
219\end{array}$ & $\begin{array}{l}245 \\
252\end{array}$ & $\begin{array}{l}256 \\
245\end{array}$ \\
\hline Изменение линейных размеров, \% & Не более 3,0 & 0,9 & 0,5 & 0,5 & 0,4 & 0,9 & 0,4 & 0,6 & 0,7 \\
\hline \multicolumn{10}{|c|}{ Технологические показатели } \\
\hline Термостабильность при $180^{\circ} \mathrm{C}$, мин & $\begin{array}{c}\text { Контр. с ДОФ } \\
28 \text { мин. }\end{array}$ & $\begin{array}{c}20 \\
\text { мин. }\end{array}$ & $\begin{array}{c}28 \\
\text { мин. }\end{array}$ & $\begin{array}{c}24 \\
\text { мин. }\end{array}$ & $\begin{array}{c}25 \\
\text { мин. }\end{array}$ & $\begin{array}{c}18 \\
\text { мин. }\end{array}$ & $\begin{array}{c}27 \\
\text { мин. }\end{array}$ & $\begin{array}{c}21 \\
\text { мин. }\end{array}$ & $\begin{array}{c}22 \\
\text { мин. }\end{array}$ \\
\hline ПТР, г $/ 10$ мин Т $=170^{\circ} \mathrm{C}, \mathrm{P}=16,6$ кгс & 4,3 & 5,1 & 5,4 & 4,4 & 4,6 & 4,0 & 4,5 & 4,8 & 5,1 \\
\hline
\end{tabular}




\section{Таблииа 7}

Результаты испытаний многослойного линолеума

\begin{tabular}{|c|c|c|c|c|}
\hline \multirow{2}{*}{$\begin{array}{c}\text { Пластификаторы, } \\
\text { используемые } \\
\text { при получении } \\
\text { полимерных пленок }\end{array}$} & $\begin{array}{c}\text { Изменение } \\
\text { линейных } \\
\text { размеров, \% не } \\
\text { более }\end{array}$ & $\begin{array}{c}\text { Удельное поверх- } \\
\text { ностное электри- } \\
\text { ческое сопротивле- } \\
\text { ние, Ом, не более }\end{array}$ & $\begin{array}{c}\text { Абсолютная } \\
\text { остаточная } \\
\text { деформация, мм, } \\
\text { не более }\end{array}$ & $\begin{array}{c}\text { Истираемость, } \\
\text { мкм, не более }\end{array}$ \\
\hline Нормы по ГОСТ 7251-77 & 0,80 & $5,0 \cdot 10^{15}$ & 0,45 & 90 \\
\hline Контрольный образец & 0,71 & $17,4 \cdot 10^{12}$ & 0,42 & 86 \\
\hline I & 0,57 & $3,4 \cdot 10^{12}$ & 0,35 & 74 \\
\hline II & 0,47 & $4,2 \cdot 10^{12}$ & 0,26 & 44 \\
\hline III & 0,52 & $3,9 \cdot 10^{12}$ & 0,34 & 45 \\
\hline IV & 0,42 & $4,1 \cdot 10^{12}$ & 0,32 & 51 \\
\hline V & 0,65 & $3,2 \cdot 10^{12}$ & 0,39 & 52 \\
\hline VI & 0,55 & $4,1 \cdot 10^{12}$ & 0,30 & 47 \\
\hline VII & 0,45 & $3,6 \cdot 10^{12}$ & 0,29 & 54 \\
\hline VIII & 0,50 & $3,8 \cdot 10^{12}$ & 0,27 & 52 \\
\hline
\end{tabular}

мостабильностью и улучшенной текучестью расплава. Согласно результатам испытаний, во всех случаях использования опытных образцов основные технологические показатели были заметно лучше, что свидетельствует об облегчении переработки соответствующих ПВХ-композиций. «Время термостабильности» и «Показатель текучести расплава» снижаются при переходе от оксипропилированных оксиэтилированных к соединениям. Это, повидимому, объясняется наличием боковой метильной группы в спиртовой части оксипропилированных соединений.

На следующем этапе получения многослойного поливинилхлоридного линолеума пленки были соединены на установке дублирования, состоящей из обогреваемых барабанов, обрезиненных прижимных валиков и транспортера охладителя. Результаты испытаний приведены в табл. 7.

Как видно из табл. 7, пластификация ПВХпленок фталатами оксиалкилированных спиртов оказывает положительное влияние на эксплуатаци- онные характеристики многослойного линолеума: «Истираемость», «Изменение линейных размеров» и «Абсолютная остаточная деформация».

\section{выводы}

Таким образом, при использовании в ПВХматериалах разработанных пластификаторов улучшаются их основные физико-механические, технологические и эксплуатационные показатели:

- при получении кабельных пластикатов улучшаются показатели «Потеря в массе при $160^{\circ} \mathrm{C} »$ И «Водопоглощение»;

- при получении ленты ПВХ липкой улучшаются показатели «Прочность при разрыве», «Относительное удлинение», «Температура хрупкости» и «Термостабильность»;

- в многослойном линолеуме показатели «Истираемость», «Изменение линейных размеров» и «Абсолютная остаточная деформация» находятся на уровне промышленного пластификатора ДОФ.

\section{REFERENCES}

1. Uilki Ch., Sammers J., Daniels Ch. Polivinilhlorid [Polyvinylchloride]. Saint-Petersburg, Profession, 2007. 728 p. (In Russian).

2. Mazitova A.K., Aminova G.K., Nafikova R.F., Deberdeev R.Ja. Osnovnye polivinilhloridnye kompozicii stroitel'nogo naznachenija [Main polyvinylchloride compositions for building purposes]. Ufa, 2013. 130 p. (In Russian).

3. Tinius K. Plastifikatory [Plasticizers]. Moscow. Chemistry, 1964. 915 p. (In Russian).

4. Barshteyn R.S., Kirilovich V.I., Nosovskiy Y.E. Plastifikatory dlja polimerov [Plasticizers for polymers]. Moscow. Chemistry, 1982. 196 p. (In Russian). 
5. Regulation (EC) №1907/2006 of the European Parliament and of the council of 18 December 2006. Official Journal of the European Union. 2007. P. 146: [Electronic source]. URL:http://eur-lex.europa.eu/oj/2006/12/direct-access.html?ojYear=2016 (Accessed date: 09.11.2016).

6. Mazitova A.K., Nafikova R.F., Aminova G.K. Plastifikatory polivinilhlorida [Plasticizers of polyvinylchloride]. Nauka i jepoha: monografija. Pod obshhej redakciej professora O.I. Kirikova [Science and epoch: monograph. Under the General editorship of Professor O. I. Kirikova]. Moscow; Voronezh, 2012. pp. 277-297. (In Russian).

7. Mazitova A.K., Aminova G.F. Gabitov A.I., Maskova, A.R., Khusnutdinov B.R., Fattakhova A.M. Razrabotka novyh plastifikatorov polivinilhlorida [Development of new plasticizers of polyvinyl chloride]. Jelektronnyj nauchnyj zhurnal «Neftegazovoe delo» [Electronic scientific journal «Oil and gas business»]. 2014. no. 12-1. pp. 120-127. (In Russian).

8. Mazitova A.K., Stepanova L.B., Aminova G.F., Maskova A.R. Razrabotka funkcional'nyh dobavok dlja polivinilhloridnyh kompozicij stroitel'nogo naznachenija [Development of functional additives for polyvinylchloride compositions for construction purposes]. Promyshlennoe proizvodstvo i ispol'zovaniejelastomerov [Industrial production and use of elastomers]. 2015. no. 2. pp. 27-31. (In Russian).

9. Faizullina G.F., Gabitov A.I., Maskova A.R., Ahmetova I.I. Plastifikacija polivinilhlorida novymi plastifikatorami [Plasticization of polyvinylchloride with new plasticizers]. Neftegazovoe delo [Oil and gas business]. 2017. Vol. 15, no. 3. pp. 106111. (In Russian).

10. Mazitova A.K., Aminova G.K., Gabitov A.I., Maskova A.R., Rahmatullina R.G. Novye plastifikatory PVH-kompozicij special'nogo naznachenija [New plasticizers of PVC compositions for special purposes]. Bashkir chemical journal. 2015. Vol. 22, no. 3. pp. 23-26. (In Russian).

11. Mazitova A.K., Aminova G.K., Maskova A.R., Sabitov I.N., Nedoseko I.V. New polyvinylchloride plasticizers. Nanotehnologii v stroitel'stve $=$ Nanotechnologies in Construction. 2017, Vol. 9, no. 6, pp. 168-180. DOI: dx.doi. org/10.15828/2075-8545-2017-9-6-168-180.

12. Mazitova A.K., Aminova G.K., Maskova A.R., Yagafarova G.G., Mazitov R.M. New plasticizers for PVC-compositions in construction. Nanotehnologii v stroitel'stve $=$ Nanotechnologies in Construction. 2017, Vol. 9, no. 4, pp. 48-63. DOI: dx.doi. org/10.15828/2075-8545-2017-9-4-48-63.

13. Maskova A.R., Aminova G.K., Karimov F.Ch., Sabitov I.N., Timofeev A.A., Mazitova A.K. Stabilization of polyvinyl chloride compounds with 1,2,4-triazine series. Nanotehnologii v stroitel'stve = Nanotechnologies in Construction. 2018, Vol. 10, no. 6, pp. 112-123. DOI: dx.doi.org/10.15828/2075-8545-2018-10-6-112-123.

14. Maskova A.R., Aminova G.K., Mazitov R.M., Faizullina G.F., Mazitova A.K. Influence of the pentaerythritol ester of oil acid on compatability of octylphenoxypropyl phthalate with polyvinyl chloride. Nanotehnologii v stroitel'stve $=$ Nanotechnologies in Construction. 2018, Vol. 10, no. 5, pp. 148-159. DOI: dx.doi.org/10.15828/2075-8545-2018-10-5-148-159.

15. Maskova A.R., Aminova G.K., Faizullina S.R., Faizullina G. F., Mazitova A.K. Production of PVC-films with specific properties. Nanotehnologii v stroitel'stve $=$ Nanotechnologies in Construction. 2018, Vol. 10, no. 4, pp. 102-115. DOI: dx.doi. org/10.15828/2075-8545-2018-10-4-102-115.

16. Maskova A.R., Mazitova A.K., Aminova G.K., Rolnik L.Z., Faizullina G.F. Investigation of the rheological properties of PVC compositions containing phthalate plasticizers. Nanotehnologii v stroitel'stve $=$ Nanotechnologies in Construction. 2018, Vol. 10, no. 3, pp. 127-137. DOI: dx.doi.org/10.15828/2075-8545-2018-10-3-127-137.

17. Mazitova A.K., Aminova G.K., Maskova A.R. Research of thermostability of phthalates of oxyalkylated alcohols. Nanotehnologii $\mathrm{v}$ stroitel'stve $=$ Nanotechnologies in Construction. 2018, Vol. 10, no. 2, pp. 157-170. DOI: dx.doi. org/10.15828/2075-8545-2018-10-2-157-170. (In Russian).

\section{СПИСОК ЛИТЕРАТУРЫ}

1. Уилки Ч., Саммерс Дж., Даниелс Ч. Поливинилхлорид. - СПб.: Профессия, 2007. - 728 с.

2. Мазитова А.К., Аминова Г.К., Нафикова Р.Ф., Дебердеев Р.Я. Основные поливинилхлоридные композиции строительного назначения. - Уфа, 2013. - 130 с.

3. Тиниус К. Пластификаторы. - М.: Химия, 1964. - 915 с.

4. Барштейн Р.С., Кириллович В.И., Носовский Ю.Е. Пластификаторы для полимеров. - М.: Химия, $1982 .-196$ с.

5. Regulation (EC) №1907/2006 of the European Parliament and of the council of 18 December 2006 // Official Journal of the European Union. - 2007. - P. 146 : [Electronic source]. URL:http://eur-lex.europa.eu/oj/2006/12/direct-access.html?ojYear=2016 (Accessed date: 09.11.2016).

6. Мазитова А.К., Нафикова Р.Ф., Аминова Г.К. Пластификаторы поливинилхлорида / Наука и эпоха: монография; под общей ред. проф. О.И. Кирикова. - Воронеж, 2011. - С. 277-297.

7. Мазитова А.К., Аминова Г.Ф., Габитов А.И., Маскова А.Р., Хуснутдинов Б.Р., Фаттахова А.М. Разработка новых пластификаторов поливинилхлорида // Нефтегазовое дело. - 2014. - Т. 12, № 1. - С. 120-127.

8. Мазитова А.К., Степанова Л.Б., Аминова Г.Ф., Маскова А.Р. Разработка функциональных добавок для поливинилхлоридных композиций строительного назначения // Промышленное производство и использование эластомеров. 2015. - № 2. - С. 27-31.

9. Файзуллина Г.Ф., Габитов А.И., Маскова А.Р., Ахметова И.И. Пластификация поливинилхлорида новыми пластификаторами // Нефтегазовое дело. - 2017. - Т. 15, o 3. - С. 106-111. 
10. Мазитова А.К., Аминова Г.К., Габитов А.И., Маскова А.Р., Рахматуллина Р.Г. Новые пластификаторы ПВХкомпозиций специального назначения // Башкирский химический журнал. - 2015. - Т. 22, № 3. - С. $23-26$.

11. Мазитова А.К., Аминова Г.К., Маскова А.Р., Сабитов И.Н., Недосеко И.В. Новые пластификаторы поливинилхлорида // Нанотехнологии в строительстве. - 2017. - Том 9, № 6. - C. 168-180. - DOI: dx.doi.org/10.15828/207585452017-9-6-168-180.

12. Мазитова А.К., Аминова Г.К., Маскова А.Р., Ягафарова Г. Г., Мазитов Р.М. Новые пластификаторы для пвхкомпозиций строительного назначения // Нанотехнологии в строительстве. - 2017. - Том 9, № 4. - C. 48-63. - DOI: dx.doi. org/10.15828/2075-8545-2017-9-4-48-63.

13. Маскова А.Р., Аминова Г. К., Каримов Ф.Ч., Сабитов И.Н., Тимофеев А.А., Мазитова А.К. Стабилизация поливинилхлоридного пластиката соединениями 1,2,4-триазинового ряда // Нанотехнологии в строительстве. - 2018. Том 10, № 6. - C. 112-123. - DOI: dx.doi.org/10.15828/2075-8545-2018-10-6-112-123.

14. Маскова А.Р., Аминова Г.К., Мазитов Р.М., Файзуллина Г.Ф., Мазитова А.К. Влияние пентаэритритового эфира масляной кислоты на совместимость октилфеноксипропилфталата с поливинилхлоридом // Нанотехнологии в строительстве. - 2018. - Том 10, № 5. - C. 148-159. - DOI: dx.doi.org/10.15828/20758545-2018-10-5-148-159.

15. Маскова А.Р., Аминова Г.К., Файзуллина С.Р., Файзуллина Г.Ф., Мазитова А.К. Получение ПВХ-пленок, обладающих специфическими свойствами // Нанотехнологии в строительстве. - 2018. - Том 10, № 4. - C. 102-115. - DOI: dx.doi.org/10.15828/2075-8545-2018-10-4-102-115.

16. Маскова А.Р., Мазитова А.К., Аминова Г.К., Рольник Л.З., Файзуллина Г.Ф. Исследование реологических свойств ПВХ-композиций, содержащих фталатные пластификаторы // Нанотехнологии в строительстве. - 2018. - Том 10, № 3. - C. 127-137. - DOI: dx.doi.org/10.15828/2075-8545-2018-10-3-127-137.

17. Мазитова А.К., Аминова Г.К., Маскова А.Р. Исследование термостабильности фталатов оксиалкилированных спиртов // Нанотехнологии в строительстве. - 2018. - Том 10, № 2. - C. 157-170. - DOI: dx.doi.org/10.15828/2075$85452018-10-2-157-170$.

\section{INFORMATION ABOUT THE AUTHORS}

Albina R. Maskova, PhD in Engineering, Associate Professor, Applied and Natural Sciences Department, Ufa State Petroleum Technological University; Mendeleev St., 195, Ufa, Bashkortostan Republic, Russia, 450080; asunasf@mail.ru;

Guliya K. Aminova, Doctor of Engineering, Professor, Applied and Natural Sciences Department, Ufa State Petroleum Technological University; Mendeleev St., 195, Ufa, Bashkortostan Republic, Russia, 450080; aminovagk@inbox.ru;

Lyubov Z. Rolnik, Doctor of Chemistry, Professor, General, Analytical and Applied chemistry Department, Ufa State Petroleum Technological University; Kosmonavtov St., 1, Ufa, Bashkortostan Republic, Russia, 450062, oax-ugntu@mail.ru;

Galiya F. Faizullina, Engineer, Applied and Natural Sciences Department, Ufa State Petroleum Technological University; Mendeleev St., 195, Ufa, Bashkortostan Republic, Russia, 450080; galiya.aminova@gmail.com;

Aliya K. Mazitova, Doctor of Chemistry, Professor, Head of Applied and Natural Sciences Department, Ufa State Petroleum Technological University; Mendeleev St., 195, Ufa, Bashkortostan Republic, Russia, 450080; elenaasf@yandex.ru.

\section{ИНФОРМАЦИЯ ОБ АВТОРАХ}

Маскова Альбина Рафитовна, к.т.н., доц. каф. «Прикладные и естественнонаучные дисциплины», ФГБОУ ВО «Уфимский государственный нефтяной технический университет»; ул. Менделеева, 195, г. Уфа, Республика Башкортостан, Россия, 450080, asunasf@mail.ru;

Аминова Гулия Карамовна, д.т.н., проф. каф. «Прикладные и естественнонаучные дисциплины», ФГБОУ ВО «Уфимский государственный нефтяной технический университет»; ул. Менделеева, 195, г. Уфа, Республика Башкортостан, Россия, 450080, aminovagk@inbox.ru;

Рольник Любовь Зелиховна, д.х.н., проф. каф. «Общая, аналитическая и прикладная химия», ФГБОУ ВО «Уфимский государственный нефтяной технический университет»; ул. Космонавтов, 1, г. Уфа, Республика Башкортостан, Россия, 450062, oax-ugntu@mail.ru;

Файзуллина Галия Фатыховна, инженер каф. «Прикладные и естественнонаучные дисциплины», ФГБОУ ВО «Уфимский государственный нефтяной технический университет»; ул. Менделеева, 195, г. Уфа, Республика Башкортостан, Россия, 450080, galiya.aminova@gmail.com;

Мазитова Алия Карамовна, д.Х.н., проф., зав. каф. «Прикладные и естественнонаучные дисциплины», ФГБОУ ВО «Уфимский государственный нефтяной технический университет»; ул. Менделеева, 195, г. Уфа, Республика Башкортостан, Россия, 450080, elenaasf@yandex.ru. 